\title{
Políticas de renovación urbana y valorización del mercado inmobiliario y de suelo. Los distritos económicos en la Ciudad de Buenos Aires
}

\section{Urban renewal policies and appreciation of real estate and land markets. The economic districts in the city of Buenos Aires}

\section{Natalia Lerena Rongvaux 1 y Carolina Gonzalez Redondo² ๑}

\begin{abstract}
RESUMEN
Desde el año 2008, la política de distritos económicos en la Ciudad de Buenos Aires nuclea las principales intervenciones orientadas a extender y profundizar el proceso de renovación urbana en áreas históricamente relegadas por el capital y el Estado. Reconociendo el papel protagónico que asume el gobierno local, el objetivo de este trabajo es presentar y analizar algunos de los efectos territoriales de esta política, en particular sobre la valorización en el mercado inmobiliario y de suelo, hacia el sur de la Ciudad. La estrategia metodológica, de tipo cuali-cuantitativa, se basó en un análisis de las ofertas de venta de terrenos, departamentos, oficinas y locales comerciales, entre los años 2003 y 2017. Esto se combinó con el análisis de documentos y entrevistas realizadas informantes clave. Entre los resultados, se verifica un proceso de valorización inmobiliaria en el sur de la Ciudad, y se discuten los efectos excluyentes de esta política.
\end{abstract}

Palabras clave: Ciudad de Buenos Aires, Renovación Urbana, Distritos Económicos, Mercado Inmobiliario, Políticas de desarrollo urbano.

\begin{abstract}
Since 2008, the Economic District Policy in the City of Buenos Aires has concentrated interventions that extend and intensify urban renovation in areas historically dismissed by capital investment and by the state. Recognizing local government's central role in this policy, this paper presents and analyzes some of the its territorial effects, specifically the appreciation of real estate and land markets in the city's southern neighborhoods. Using a methodology that is both qualitative and quantitative, this study evaluates sales offerings of plots of land, apartments, offices and storefronts from 2003 to 2017, and considers archival sources and interviews with key informants to verify the appreciation of real estate values in the south of the city, allowing for a discussion about the Economic District Policy's exclusionary effects.
\end{abstract}

Keywords: Buenos Aires, Urban Renewal, Economic Districts, Real-estate Market, Urban Development Policies 
Desde el año 2008, el Gobierno de la Ciudad de Buenos Aires (GCBA) promueve la radicación de empresas e instituciones de una misma actividad económica en áreas específicas de la ciudad, mediante la concesión de beneficios impositivos, financieros e inmobiliarios y la creación de infraestructura, entre otras intervenciones. Estos distritos económicos -presentados por el ejecutivo local como una nueva propuesta para resolver el "desequilibrio territorial" y "desarrollar la zona sur"- profundizan y amplían una serie de políticas de renovación urbana llevadas a cabo en la zona sur de la ciudad de Buenos Aires desde fines de los ' 80.

Esta propuesta de renovación urbana -al igual que otras que proliferan en las ciudades latinoamericanas- se enmarca en el denominado urbanismo neoliberal (Pradilla Cobos, 2009; Jaramillo, 2014), que se consolida a partir de los años ' 80 con la reconfiguración del modo de producción capitalista. Este urbanismo neoliberal, en lugar de regular el mercado inmobiliario, se pliega a su dinámica generando las condiciones para una inversión segura, en consonancia con un tipo de gestión urbana -el empresarialismo urbano-, en el que prima una visión empresarial sobre la ciudad y sobre lo público (Harvey, 1989). De manera complementaria, esta política de distritos retoma parte de las premisas del modelo de clusters (Porter, 1995; 1998) -de gran circulación en ámbitos académicos y de gestión pública-, y lo combina con elementos provenientes de la economía creativa o ciudades creativas (Lash y Urry, 1994; Molotch, 1996; Pratt, 1997; Scott, 1996; Caravaca et al, 2013; Lazzeretti, 2008). Estas premisas son, entre otras, la relación de causalidad entre desarrollo económico y urbano; la asunción acrítica del imperativo de la competitividad; el rol del Estado como facilitador y creador del "clima de negocios"; la concepción del territorio como fuente de recursos, de "ventajas competitivas"; y el predominio de una mirada armónica y libre de conflicto sobre el territorio y sus actores ${ }^{3}$.

Una particularidad de los distritos porteños -que se aleja, en parte, de la prescripción de estos modelos de economías de aglomeración- es su énfasis en el desarrollo inmobiliario. En un contexto de creciente mercantilización en la producción y gestión del territorio metropolitano (Pírez, 2016), el "desarrollo" de "áreas degradadas" se asocia a la densificación y a la valorización inmobiliaria del sur, buscando equipararla con los índices del norte. Así, junto con otras iniciativas incluso más recientes ${ }^{4}$, los distritos económicos tienden a incorporar al mercado inmobiliario y de suelo una gran cantidad de metros cuadrados vacantes, "destrabando" una enorme brecha de renta, y avanzando sobre las últimas fronteras del capital inmobiliario en la ciudad5.

El objetivo de este trabajo es, precisamente, indagar sobre este aspecto de la política de distritos; es decir, su énfasis en el desarrollo inmobiliario. Para ello, analizamos, por un lado, el modo en que el Estado local incentiva -mediante diversos mecanismos- las inversiones inmobiliarias en los distintos distritos; y cómo el sector privado responde diferencialmente a estos incentivos en cada uno de ellos. Por el otro, centramos el análisis en el proceso -también diferencial- de valorización

\footnotetext{
Para profundizar en el vínculo de la política de distritos con estos modelos de economías de aglomeración, ver Gonzalez Redondo (2018).

Como la venta de terrenos y edificios públicos para desarrollos inmobiliarios y urbanos en toda la ciudad; la sanción de un nuevo Código Urbanístico, a fines de 2018, que habilita la densificación de las áreas más consolidadas del norte y centro de la Ciudad; y la (re)urbanización de un conjunto de villas de emergencia, que incorpora nuevo suelo al mercado formal.

5 Un ex Ministro de Desarrollo Urbano de la ciudad de Buenos Aires, nos comentaba en una entrevista reciente que el objetivo de la gestión era acelerar el desarrollo de la zona sur para que alcance la dinámica del área norte. De este modo se revertiría el desequilibrio territorial diagnosticado en diversos documentos oficiales.
} 
inmobiliaria y del suelo de la zona sur de la ciudad, a partir de la implementación de los distritos económicos y las intervenciones que éstos engloban.

El trabajo se organiza de la siguiente manera. En primer lugar, se presenta una breve revisión bibliográfica, explicitando el andamiaje teórico que enmarca el análisis, así como también los antecedentes del caso. En un segundo lugar, se expone la metodología utilizada para la producción y análisis de la información empírica utilizada. En tercer lugar, se profundiza en la caracterización del caso de estudio y se presentan los principales resultados a los que arribó la investigación. Finalmente, se sintetizan los principales hallazgos y se concluye con una reflexión final.

\section{Antecedentes del caso y consideraciones teóricas}

Este trabajo indaga sobre los impactos territoriales de una política que engloba diversas iniciativas de renovación urbana en el sur de la ciudad de Buenos Aires. En este sentido, dialoga con dos grandes líneas de investigación. En primer lugar, con aquellos estudios que analizan las características y la evolución del mercado del suelo en la ciudad de Buenos Aires (Baer y Kauw, 2016) y su región metropolitana (Baer, 2011; Vecslir y Ciccolella, 2011). Estos análisis dan cuenta de un fuerte patrón de valorización territorial de las áreas norte y centro del Área Metropolitana de Buenos Aires (AMBA), y una zona sur que aun constituye un área de vacancia para el capital. Algunos de esos trabajos señalan, además, la tendencia al aumento del esfuerzo requerido por las familias trabajadoras para residir en la ciudad (Baer y Kauw, 2016). Recientemente, algunos autores comienzan a preguntarse si las políticas públicas orientadas a valorizar la zona sur de la ciudad de Buenos Aires, estarían modificando este patrón (Goicochea, 2017; Baer y Kauw, 2016).

En segundo término, el presente artículo dialoga con aquellos estudios urbanos, de larga tradición en nuestra ciudad, que analizan las políticas de renovación orientadas a la zona sur de la ciudad de Buenos Aires (Herzer, 2008; Díaz, Ferme y Raspall, 2010; Socoloff et al., 2012; Goicoechea, 2016; Rodríguez y Di Virgilio, 2014; Guevara, 2015; Arqueros Mejica, 2017). De metodologías principalmente cualitativas, estos trabajos ponen el foco en el análisis de la política pública a partir de la realización de entrevistas y el relevamiento de documentos y notas periodísticas. La utilización de información demográfica censal y de mercado inmobiliario también está presente en estos trabajos, principalmente a través de datos secundarios, basados en publicaciones oficiales.

En cuanto a los distritos económicos, encontramos un conjunto de trabajos que echan luz sobre diferentes aspectos de alguno de ellos en particular. Parte de estos estudios se centran en las transformaciones socio-territoriales que estas iniciativas están propiciando, y enfatizan en la dinámica inmobiliaria y en los procesos de valorización del suelo que tienen lugar en estos barrios (Díaz, Ferme, y Raspall, 2010 y, en especial, las investigaciones de Goicoechea, 2016; 2017; 2018). Otros ponen el foco en la dimensión simbólica de estas transformaciones (Hernández, 2015, 2017, Thomasz, 2016, 2017; mientras que un grupo de trabajos se pregunta por las racionalidades políticas presentes en los discursos de las autoridades locales en relación a los distritos (Socoloff et al., 2012; Socoloff, 2013). Son más escasos, en tanto, los trabajos que caracterizan -en clave comparativa- los distritos ubicados en el sur de la Ciudad, dando cuenta de los incentivos diferenciados y las transformaciones heterogéneas que la acción estatal promueve en cada caso. 
Apoyándose en estos estudios previos, el presente artículo indaga sobre el proceso de valorización inmobiliaria desplegado en los barrios comprendidos por los distritos del sur. Entre sus principales aportes, este trabajo implica: a) ampliar las tipologías inmobiliarias analizadas, en la medida en que estudios previos analizan exclusivamente el precio de terrenos, mientras que aquí se incluye además el comportamiento de oficinas, locales comerciales y viviendas, b) analizar -en clave comparativa- la dinámica inmobiliaria diferencial entre los distintos distritos económicos del sur; y c) ofrecer información cuantitativa de primera mano, en particular tomando como indicador de valorización la variación porcentual entre períodos.

En este trabajo, se concibe a las políticas de renovación como aquellas acciones e inversiones tendientes a transformar y mejorar material y simbólicamente el entorno urbanístico de un área determinada (Diaz Parra, 2013; Rodríguez, 2015). La mayoría de los estudios urbanos críticos sobre procesos de renovación urbana parten desde hipótesis de gentrificación (Smith, 1979; Marcuse, 1985; Slater, 2009; Janoschka y Sequera, 2014; Lopez Morales, 2014; Blanco y Apaolaza, 2016; Socoloff et al., 2012; Herzer, 2008). Este concepto, de gran utilidad heurística, ha demostrado sin embargo tener algunas limitaciones teórico-metodológicas, fundamentalmente debido a: a) un uso a menudo demasiado elástico, producto de intentar explicar fenómenos de naturaleza distinta bajo un mismo concepto, b) una extrapolación acrítica desde interpretaciones anglosajonas hacia realidades latinoamericanas y c) la dificultad que implica "medir" concretamente el desplazamiento, rasgo inherente al proceso en la mayoría -aunque no todas- las acepciones del término.

Aunque estos debates han resultado muy interesantes y fructíferos, excede los límites de este trabajo retomarlos. En cambio, partiendo de reflexiones generales sobre la lógica de realización de la valorización inmobiliaria en las ciudades latinoamericanas (Pradilla, 2009; Jaramillo, 2014), y atendiendo al carácter excluyente de las políticas de renovación urbana, (Carman, Vieira da Cunha y Segura, 2013), se propone interpretar las transformaciones en curso en la zona sur de la ciudad a través de la noción de renovación urbana excluyente. Con esto nos referimos a todo proceso que, orientado tanto por políticas públicas como por dinámicas privadas, tiende a restringir el uso, apropiación y residencia en áreas de centralidad urbana, por parte tanto de grupos sociales que actualmente las aprovechan como de potenciales usuarios, por razones económicas. Esta interpretación, en sintonía con reflexiones anteriores en la misma línea (López Morales, 2014; Blanco y Apaolaza, 2016; Apaolaza y Bosoer (2014), recoge las lecturas sobre desplazamiento excluyente de Marcuse (Slater, 2009) y gentrificabilidad de Díaz Parra (2013). Se trata de una interpretación amplia con respecto a las formas posibles que puede tomar en cada caso, pero restringida en cuanto a las condiciones que deben presentarse, y permite sortear -al menos provisoriamente- los debates teóricos, políticos y metodológicos en torno al concepto de gentrificación, conservando su potencial heurístico. Como hipótesis de trabajo, señalamos que las condiciones que se tejen entre las intervenciones englobadas en la política de distritos económicos y sus efectos en la valorización del mercado inmobiliario y de suelo se constituyen como los principales indicadores de renovación urbana excluyente.

\section{Consideraciones metodológicas}

El trabajo se apoya en una estrategia metodológica combinada. Por un lado, hacemos un análisis cuantitativo de las ofertas de venta de diferentes tipologías inmobiliarias -terrenos, departa- 
mentos, oficinas y locales comerciales- (Ver Cuadro $N^{\circ} 1$ ) para una serie de unidades territoriales especialmente construidas, entre los años 2003 y 2017. Por el otro, trabajamos con herramientas cualitativas, tales como entrevistas semi-estructuradas a informantes clave y diversas fuentes bibliográficas y documentales secundarias (marcos normativos, versiones taquigráficas de sesiones de la Legislatura porteña y de audiencias públicas, gacetillas de prensa y materiales gráficos elaborados por los organismos públicos involucrados en la política).

La estrategia cuantitativa se basó en un relevamiento periódico realizado por el Ministerio de Desarrollo Urbano del Gobierno de la Ciudad de Buenos Aires (MDU-GCBA), y de relevamientos propios, a partir de buscadores web especializados, principalmente Zona Prop, Argenprop, Buscainmueble e Inmuebles Clarín. En el caso de los relevamientos oficiales, se controlaron, validaron y eventualmente corrigieron los errores originales de los datos ${ }^{6}$.

A partir de esta información, se elaboró una base de datos georreferenciada para diferentes unidades territoriales significativas de la Ciudad, construidas de acuerdo al objetivo del trabajo. Dichas unidades territoriales responden a una decisión metodológica y no necesariamente guardan correspondencia jurídica (Figura $\mathrm{N}^{\circ} 1$ ). De los datos de las ofertas publicadas, fueron seleccionados: localización, superficie (M2), y precio de oferta (en dólares). A partir de esto, se calculó el precio por metro cuadrado por cada oferta.

\section{Cuadro $\mathrm{N}^{\circ} 1$ :}

Tipologías inmobiliarias analizadas

\begin{tabular}{|c|c|c|}
\hline TIPOLOGÍA INMOBILIARIA & PERÍODO ANALIZADO & CANTIDAD DE OFERTAS PARA TODA LA CIUDAD \\
\hline TERRENOS & $2003-2017$ & 22.048 \\
DEPARTAMENTOS & $2003-2016$ & 178.342 \\
\hline OFICINAS & $2014-2016-2017$ & 4.843 \\
\hline LOCALES COMERCIALES & $2005-2017$ & 17.491 \\
\hline
\end{tabular}

Fuente: elaboración propia en base a relevamientos propios y de MDU-GCBA

Como ya ha sido señalado (Baer, 2011, Goicoechea, 2016, 2019), este relevamiento cuenta con una serie de limitaciones metodológicas, a saber: a) se estima que el precio final de compra/venta en las transacciones locales es inferior al publicado en la oferta, oscilando entre un $5 \%$ y un $15 \%$; b) la cantidad de ofertas oscila a lo largo de los años por motivos que exceden las ofertas efectivas en el mercado, tales como cambios en las metodologías de relevamiento; c) puede aparecer duplicación de iguales ofertas entre varios buscadores. Sin embargo, desde el punto de vista estadístico, ninguna de ellas invalida los resultados. Por otra parte, este relevamiento es la única forma en Argentina para estimar el mercado inmobiliario, ya que no es posible acceder a registros de compraventa. 


\section{Figura N01:}

Unidades territoriales de análisis. Ciudad de Buenos Aires.

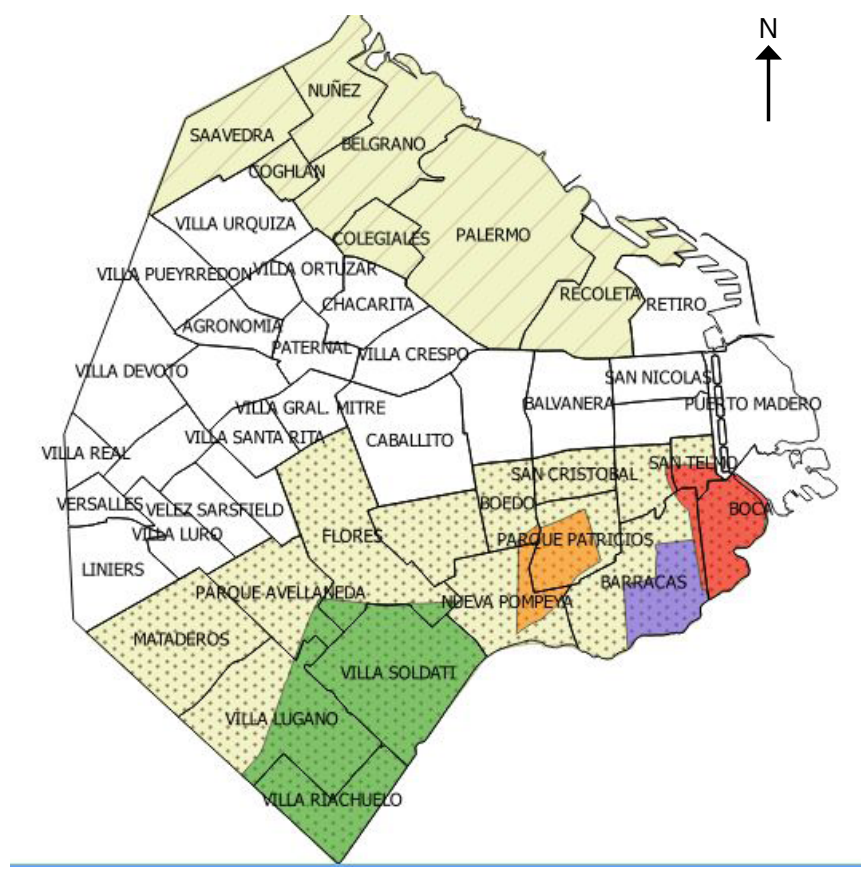

Unidades territoriales

Unidades teritoriales distritos-econ-conDG-geo

Barrios del norte DISTRITO DE DISEÑO

Bamios del sur DISTRITO DE LAS ARTES

- DISTRITO DEL DEPORTE

$\square$ DISTRITO TEANOLOGICO
Barrics

Fuente: elaboración propia

Por último, para el análisis diacrónico, en los casos en los que se contó con series extensas de datos, se agruparon los años a partir de periodizaciones, elaboradas en función del surgimiento y las distintas etapas de consolidación de cada uno de Distritos Económicos ${ }^{7}$. Esto permitió un análisis global, evitando las oscilaciones interanuales, priorizando la tendencia general de valorización. Dichas periodizaciones, además, guardan correspondencia con otras que tienen en cuenta variaciones generales del mercado inmobiliario de toda la Ciudad (Baer y Di Giovambattista, 2018), a los fines de no imputar a la política de Distritos Económicos movimientos que responden a dinámicas generales, como pueden ser medidas macroeconómicas, intervención a través de créditos, entre otras.

A partir de todo esto, entonces, fueron analizadas dos variables principales: a) evolución de la cantidad de ofertas para todas las tipologías, en las diferentes unidades territoriales de análisis; b) evolución del precio promedio del metro cuadrado en dólares ofrecido para todas las tipologías,

\footnotetext{
Cabe mencionar que, debido a la disponibilidad de datos, existen diferencias entre las periodizaciones realizadas para las distintas tipologías inmobiliarias (ver Cuadro $N^{\circ}$ 1). Sin embargo, para los casos en los que se contó con una serie extensa, todas las periodizaciones responden a cortes significativos para el análisis de la política de Distritos Económicos, en función de sus etapas: anteriores al surgimiento, de implementación, de consolidación y de maduración de la política. Así pues, para el caso de terrenos y departamentos, se agrupó de la siguiente manera: (1) 2003-2005, período ajeno a la creación de la política; (2) 2006-2008; período inmediatamente anterior a la creación del Distrito Tecnológico (3) 2009-2011; etapa previa a implementación de Distrito del Diseño y de las Artes y etapa de implementación del Distrito Tecnológico (4) 2012-2014, segunda etapa de implementación del Distrito Tecnológico y creación del Distrito de las Artes y del Diseño; y (5) 2015-2017, etapa de consolidación del Distrito Tecnológico y de implementación del Distrito del Deporte. Se hicieron algunas pequeñas modificaciones en la periodización de los locales comerciales, debido a la disponibilidad de datos recién a partir de 2005. Por último, para el caso de oficinas no se realizaron periodizaciones, por con contar una serie de tan sólo tres años.
} 
en las diferentes unidades territoriales de análisis ${ }^{8}$. El análisis de estos datos se complementó con información sobre la dinámica inmobiliaria de las zonas comprendidas por los distritos, obtenida a partir de entrevistas a informantes clave. En algunos casos, este cruce permitió profundizar y apoyar los hallazgos derivados del análisis cuantitativo; mientras que en otros sirvió para reponer información que no es posible recuperar del análisis cuantitativo, ya sea por el tipo de desagregación o por la falta de datos para el período observado.

\section{El sur de Buenos Aires: condiciones de vida y políticas de renovación}

\section{Condiciones de vida en los barrios del sur de la ciudad}

La ciudad de Buenos Aires está situada sobre el margen del Río de la Plata, tiene una superficie aproximada de $200 \mathrm{~km} 2$, y está delimitada al sur por el Riachuelo, y al norte y oeste por la avenida de circunvalación General Paz. Según el Censo Nacional de Población, Hogares y Vivienda (CNPHV) de 2010, cuenta con una población de casi tres millones de habitantes, a los que se suman otros tres millones de personas que transitan diariamente por ella para desarrollar sus actividades laborales, educativas, recreativas, etc 9 . Junto con los 24 partidos de la primer y segunda corona y otros 16 municipios del tercer anillo metropolitano ${ }^{10}$, forma parte de la Región Metropolitana de Buenos Aires (RMBA), la mancha urbana de casi 14 mil kilómetros en la que habitan aproximadamente 15 millones de personas, lo que representa el $37 \%$ de la población del país (CNPHV, 2010). Desde fines del siglo XIX, la ciudad de Buenos Aires es la capital federal del país y, desde 1996, con la sanción de su propia constitución, se transforma en la Ciudad Autónoma de Buenos Aires (CABA). Este proceso de autonomización implica, en la práctica, una elevación del nivel administrativo, pasando de ser un municipio a adquirir las mismas competencias que las otras 23 provincias del país. Asimismo, en 2005 se sanciona la ley №1.777 y la ciudad pasa a estar dividida en 15 comunas, introduciendo otro nivel de gestión político-administrativo.

A pesar de ser la jurisdicción más rica del país ${ }^{11}, 756.000$ personas -es decir una de cada cuatro- viven en condiciones habitacionales críticas en la ciudad de Buenos Aires, un tercio de ellas en villas de emergencia y asentamientos, que crecieron un 52\% en las últimas décadas (CEyS, 2014). Las comunas 1,4 y 8 son, como veremos, las que presentan condiciones de vida más vul-

\footnotetext{
3 La utilización del indicador promedio por metro cuadrado se corresponde con la metodología de trabajos académicos (Baer, 2011; Baer y Kauw, 2016; Baer y Di Giovambattista, 2018) e informes de gestión (SSPLAN-MDU, 2017) anteriores, permitiendo la comparabilidad.

9 Ministerio de Desarrollo Urbano, Subsecretaría de Planeamiento de la ciudad de Buenos Aires (2011), "Modelo Territorial 2010-2060", edición literaria a cargo de Mauricio Macri, Daniel Chain y Héctor Lostri, Buenos Aires.

10 La RMBA está integrada por la CABA y los siguientes partidos de la provincia de Buenos Aires: Almirante Brown, Avellaneda, Berazategui, Berisso, Brandsen, Campana, Cañuelas, Ensenada, Escobar, Esteban Echeverría, Exaltación de la Cruz, Ezeiza, Florencio Varela, General Las Heras, General Rodríguez, General San Martín, Hurlingham, Ituzaingó, José C. Paz, La Matanza, La Plata, Lanús, Luján, Lomas de Zamora, Malvinas Argentinas, Marcos Paz, Merlo, Moreno, Morón, Pilar, Presidente Perón, Quilmes, San Fernando, San Isidro, San Miguel, San Vicente, Tigre, Tres de Febrero, Vicente Lopez y Zárate.

En 2015, la ciudad de Buenos Aires concentraba el 22,4\% del Valor Agregado Bruto nacional, en un territorio donde sólo reside el 7,2\% de la población total del país. Así, mientras que el PBI nacional per cápita fue, para ese año, de 12.256usd, el Producto Bruto Geográfico (PBG) per cápita de la ciudad ascendió a 38.721usd. Estos datos corresponden al último Informe sobre Producto Bruto Geográfico de la ciudad de Buenos Aires, con datos de 2015, elaborado por la Dirección General de Estadísticas y Censos del Ministerio de Hacienda del GCBA (DGEyC, 2015).
} 
nerables, estas últimas dos -junto con parte de las comunas 3, 7 y 9-conforman la denominada "zona sur" de Buenos Aires ${ }^{12}$. Cuatro de los cinco distritos económicos se ubican, precisamente, en esta zona sur y parte de su justificación radica -al menos a nivel discursivo- en la necesidad de "integrar la ciudad" y para ello "desarrollar su zona sur". Así, la política de distritos se presenta como una nueva solución al "deterioro" de la zona sur de Buenos Aires y su "desequilibrio" con respecto al norte, un problema que se fue construyendo como cuestión (Oszlak y O'Donnell, 1981) a lo largo del proceso histórico de urbanización de la ciudad.

Mientras que el "deterioro" que aparece en los sucesivos diagnósticos oficiales remite al espacio construido; el "desequilibrio" expresa, más bien, una gran desigualdad en las condiciones de vida de la población que habita a uno y otro lado de la Av. Rivadavia ${ }^{13}$. De hecho, al comparar algunos indicadores seleccionados (ver Cuadro $N^{\circ} 2$ ), se observa que los valores que arrojan las comunas del sur (4 y 8 ) son en todos los casos más críticos que el promedio de la ciudad; siendo la brecha aún mayor si se contrasta con las comunas 2 y 13, que presentan en general las mejores condiciones socio-económicas y habitacionales. Así, por ejemplo, se observa que en las comunas 4 y 8 la proporción de hogares con al menos una NBI es el doble que la de la ciudad, y representa seis veces más que la de las jurisdicciones 2 y 13. La tasa de desocupación también es notablemente más alta en las comunas del sur, y el ingreso medio es casi la mitad que el de las comunas más acomodadas ( 2 y 3 ).

En relación a los indicadores socio-habitacionales, se observa que la proporción de viviendas deficitarias, hogares con tenencia irregular y con hacinamiento (crítico o por cohabitación) es en todos los casos muy superior para las comunas 4 y 8 , siendo esta última la más afectada. Estas desigualdades también se ponen de manifiesto en la provisión de servicios públicos ya que, a pesar de tener una amplia cobertura en la ciudad de Buenos Aires, su insuficiencia se concentra también en los barrios del sur. Por último, estos indicadores guardan relación con la proporción de habitantes de la comuna que viven en villas y asentamientos informales, que en las jurisdicciones 4 y 8 representan, respectivamente, un 16\% y un 32\% de su población, mientras que en el conjunto de la ciudad alcanza al $6 \%$.

\section{Cuadro $N^{\circ} 2$ :}

Indicadores seleccionados sobre condiciones de vida en las comunas seleccionadas,

Ciudad Autónoma de Buenos Aires (CABA).

\begin{tabular}{|l|l|c|c|c|c|c|}
\hline & & $\begin{array}{c}\text { Comuna } \\
4\end{array}$ & $\begin{array}{c}\text { Comuna } \\
8\end{array}$ & $\begin{array}{c}\text { Comuna } \\
2\end{array}$ & $\begin{array}{c}\text { Comuna } \\
13\end{array}$ & CABA \\
\hline \multirow{4}{*}{$\begin{array}{l}\text { ASPECTOS } \\
\text { DEMOGÁFICOS }\end{array}$} & Cantidad de población & 218.245 & 187.237 & 157.932 & 231.331 & 2.890 .151 \\
\cline { 2 - 7 } & $\%$ Población infantil & $20,96 \%$ & $25,23 \%$ & $11,02 \%$ & $14,13 \%$ & $16,35 \%$ \\
\cline { 2 - 7 } & $\begin{array}{l}\text { Variación intercensal de } \\
\text { población 2001-2010 }\end{array}$ & $1,30 \%$ & $15,80 \%$ & $-4,60 \%$ & $1,40 \%$ & $4,10 \%$ \\
\cline { 2 - 7 } & Tamaño medio hogares & 2,8 & 3,2 & 2,1 & 2,3 & 2,5 \\
\hline
\end{tabular}

\footnotetext{
Las 15 comunas constituyen un nuevo nivel de gestión político-administrativo de la ciudad de Buenos Aires, desde el año 2005 , en que se sancionó la ley 1.777 .

13 Tal como se observa en la Figura N², la Avenida Rivadavia es el límite físico y simbólico entre el norte y el sur de la ciudad. Para un ex funcionario de alto rango, en tanto, el límite está dado por la traza de la autopista 25 de Mayo: "la ciudad empezaba a no ser ciudad de Buenos Aires a partir de la autopista, que funciona como una valla, como una muralla" (Entrevista realizada en enero de 2019).
} 


\begin{tabular}{|c|c|c|c|c|c|c|}
\hline & & $\begin{array}{c}\text { Comuna } \\
4\end{array}$ & $\begin{array}{c}\text { Comuna } \\
8 \\
\end{array}$ & \begin{tabular}{|c|} 
Comuna \\
2 \\
\end{tabular} & $\begin{array}{c}\text { Comuna } \\
13\end{array}$ & CABA \\
\hline \multirow{3}{*}{$\begin{array}{l}\text { ASPECTOS } \\
\text { SOCIO-ECO- } \\
\text { NÓMICOS }\end{array}$} & $\begin{array}{l}\% \text { de hogares con al } \\
\text { menos una NBI }\end{array}$ & $12,66 \%$ & $11,31 \%$ & $2,05 \%$ & $1,87 \%$ & $5,98 \%$ \\
\hline & $\begin{array}{l}\text { Tasa de desocupación } \\
(2016)\end{array}$ & $9,10 \%$ & $13,00 \%$ & $5,40 \%$ & $3,80 \%$ & $8,00 \%$ \\
\hline & $\begin{array}{l}\text { Ingreso medio } 3 e r \\
\text { trimestre } 2016^{\star *}\end{array}$ & \multicolumn{2}{|c|}{$\$ 12.161$} & \multicolumn{2}{|c|}{$\$ 22.134$} & $\$ 16.100$ \\
\hline \multirow{8}{*}{$\begin{array}{l}\text { CONDICIONES } \\
\text { SOCIO-HABITA- } \\
\text { CIONALES }\end{array}$} & $\begin{array}{l}\text { \% de viviendas } \\
\text { deficitarias }\end{array}$ & $11,96 \%$ & $11,38 \%$ & $0,95 \%$ & $1,04 \%$ & $4,44 \%$ \\
\hline & $\begin{array}{l}\% \text { de hogares con } \\
\text { tenencia irregular }\end{array}$ & $14,23 \%$ & $18,26 \%$ & $9,07 \%$ & $9,94 \%$ & $11,65 \%$ \\
\hline & $\begin{array}{l}\% \text { de hogares con } \\
\text { hacinamiento crítico }\end{array}$ & $3,58 \%$ & $5,07 \%$ & $0,45 \%$ & $0,39 \%$ & $1,53 \%$ \\
\hline & $\begin{array}{l}\% \text { de hogares con } \\
\text { hacinamiento por } \\
\text { cohabitación }\end{array}$ & $14,10 \%$ & $25,53 \%$ & $5,68 \%$ & $4,88 \%$ & $9,56 \%$ \\
\hline & $\begin{array}{l}\% \text { de hogares sin agua } \\
\text { de red }\end{array}$ & $0,68 \%$ & $0,95 \%$ & $0,27 \%$ & $0,12 \%$ & $0,40 \%$ \\
\hline & $\begin{array}{l}\% \text { de hogares sin } \\
\text { cloacas }\end{array}$ & $5,11 \%$ & $6,33 \%$ & $0,61 \%$ & $0,47 \%$ & $1,84 \%$ \\
\hline & $\begin{array}{l}\% \text { de hogares sin gas } \\
\text { de red }\end{array}$ & $22,09 \%$ & $36,38 \%$ & $2,62 \%$ & $2,48 \%$ & $7,82 \%$ \\
\hline & $\begin{array}{l}\text { \% población sobre la } \\
\text { comuna que vive en } \\
\text { villas }\end{array}$ & $16,29 \%$ & $32,47 \%$ & $0,31 \%$ & - & $5,66 \%$ \\
\hline
\end{tabular}

Todos los datos corresponden al año 2010, salvo los casos en los que se indica lo contrario.

${ }^{*}$ Montos expresados en pesos y por zona (norte y sur), tal como lo releva la ETOI.

Fuente: Goicochea (2018). Elaborado en base al CNPHV 2010, EAH CABA 2016, ETOI CABA 2016 y CEyS, 2013.

Este diagnóstico de un sur "deteriorado" y "desequilibrado" con respecto al norte de la ciudad fue abordado tempranamente, tanto desde la gestión pública, en sucesivos documentos oficiales ${ }^{14}$, como desde la academia (ver Scobie, 1977; Romero, 1983; 2009; Gorelik, 1998; 2004; Silvestri y Gorelik, 2000; Herzer, 2008; Rodríguez y Di Virgilio, 2011). Aquí nos interesa resaltar que, aunque se presente como algo dado, este diagnóstico es, por el contrario, resultado del proceso histórico de desarrollo desigual de esta ciudad, que guarda relación con la historia de su urbanización. La falta de interés por parte del mercado, la acción y omisión por parte del Estado y las acciones de la población de menores recursos tendientes a procurarse un espacio en la ciudad explican, en gran parte, las características socio-territoriales actuales de la zona sur (Goicochea, 2018). Las políticas urbanas de la última dictadura (1976-1983) constituyen una bisagra, en la medida en que dejaron profundas huellas en el tejido urbano, que prepararon las condiciones para el proceso de renovación posterior. Así, el neoliberalismo realmente existente (Theodore, Peck y

\footnotetext{
14 Son muchos los planes generales que reconocen este "desequilibrio" entre norte y sur. El primero de ellos fue el Plan Noel (1925). Luego, le siguieron el Plan Director o Plan Le Corbusier (1938-1940), el Plan Director (1958-1962) y el Esquema Director del año 2000 (1969). Más recientemente, encontramos el Plan Urbano Ambiental (2008) y el Modelo Territorial (2009). A estos se suman una gran cantidad de planes, proyectos y normativas parciales que elaboraron propuestas para algunos de los barrios del sur. Para profundizar, consultar Goicoechea (2016).
} 
Brenner, 2009) en la ciudad de Buenos Aires se fue configurando desde mediados de la década del '70 a través de un proceso de sedimentación de diversos planes y proyectos urbanos, los sucesivos ajustes del aparato burocrático del Estado. Si bien se reconocen diversos matices, temporalidades y reacomodamientos en función de los conflictos que se van suscitando, se mantiene como denominador común el rol activo del Estado para propiciar las transformaciones urbanas en curso.

\section{El sur como foco de intervención}

Desde la autonomización política de la ciudad, en el año 1996, las políticas hacia el sur se orientaron a "incorporar el sur al norte" (Rodriguez y Di Virgilio, 2014), conduciendo el Estado un proceso activo de renovación urbana que tiene su correlato en la progresiva concentración del gasto público en esta área de la ciudad, particularmente en las comunas 4 y 8 (Di Virgilio y Guevara, 2014; Guevara, 2010; Rodríguez, Bañuelos y Mera, 2008). Las políticas de renovación estuvieron primero concentradas en las zonas más cercanas al microcentro porteño, luego se fueron extendiendo hacia el sudeste, abarcando los barrios de La Boca y Barracas y, más recientemente, han llegado a los barrios de la comuna 8, pasando previamente por Parque Patricios.

En San Telmo y La Boca, las primeras iniciativas de renovación se articularon con procesos de activación patrimonial y valorización turística (Almiron, Bertoncello y Troncoso, 2005; Gómez y Zunino Singh, 2008; Rodriguez y Di Virgilio, 2014). En el barrio de Barracas, en tanto, la renovación es más reciente y fragmentada, limitándose a algunos desarrollos inmobiliarios a cargo de privados consistentes, en su mayoría, en la reconversión de viejas usinas y fábricas en complejos habitacionales de alta gama (Scillamá, 2014). En este caso, el Estado local acompañó el proceso mediante algunas intervenciones puntuales a comienzos del nuevo milenio (creación del Centro Metropolitano del Diseño; renovación de Colonia Sola, intervención en el Pasaje Lanín). Las políticas de renovación urbana dirigidas por el Estado cobraron más fuerza en Barracas recién a partir de 2008, con los proyectos de creación de los distritos gubernamental ${ }^{15}$ y del diseño. Algo similar sucedió en Parque Patricios, que recién mostró signos de renovación a partir de la conformación del distrito tecnológico en 2008 (Goicoechea, 2016).

En cuanto al sudoeste de la ciudad, particularmente en la comuna 8, las políticas de renovación se restringieron a algunos proyectos realizados en articulaciones público-privadas bajo la órbita de la Corporación Buenos Aires Sur (CBAS), que implicaron la transferencia y/o concesión de inmuebles o terrenos públicos de dominio privado (ver Arqueros Mejica, 2013; 2017). La renovación en esta zona de la ciudad cobra un mayor impulso a partir de 2014, con la creación del distrito del deporte y la realización de la Villa Olímpica para los Juegos Olímpicos de la Juventud, llevados a cabo en octubre 2018 (ver Arqueros Mejica, 2017). Por último, cabe señalar el proceso de saneamiento de la cuenca Matanza-Riachuelo, que se articula con los procesos de renovación en toda el área sur. Este proceso implica, entre otras cosas, la reconversión y control de las industrias contaminantes y la relocalización de familias que habitan a ambos márgenes de la ribera ${ }^{16}$.

\footnotetext{
EI DG buscaba "revitalizar" un sector del barrio de Barracas a partir de la refuncionalización de un predio de 40 hectáreas donde funcionaban tres hospitales públicos de atención a la salud mental y otras instituciones públicas. Debido a la fuerte resistencia por parte de organizaciones sociales y trabajadores del hospital Borda el proyecto fue interrumpido, mudándose el GCBA a otras dos sedes en la zona sur de la ciudad, la nueva sede de gobierno frente al Parque Patricios y el ex edificio Canale frente al Parque Lezama (ver Figura No2).

16 Para profundizar ver Merlinsky (2013); Scharager (2017)
} 
Luego de la fuerte crisis económica del 2001, estos procesos de renovación urbana se inscriben en un contexto de metropolitano de creciente valorización inmobiliaria. En la ciudad de Buenos Aires, los procesos de verticalización, densificación y valorización del suelo se concentraron primero (2002-2007), en los barrios del norte. A partir de 2008, coincidiendo con la política de distritos, esta tendencia alcista se extendió hacia la zona sur, evidenciando un cambio en los ritmos de valorización de ambas áreas (Baer y Kauw, 2016; CEyS, 2016).

Estas dinámicas del mercado inmobiliario, junto con las dificultades para acceder al crédito hipotecario, restringen las posibilidades para acceder a una vivienda en propiedad para los sectores medios y medios bajos, dando lugar a un proceso de inquilinización en la ciudad de Buenos Aires (ACIJ, 2016; CEyS, 2016). El aumento sostenido en los precios de los alquileres del mercado formal -junto con las crecientes exigencias para acceder a un contrato de alquiler - presiona, a su vez, para que aquellas familias más vulnerables tengan que resolver su situación ${ }^{17}$ habitacional en la informalidad (CEyS, 2016; ACIJ, 2016). Si bien estos procesos se observan en el conjunto de la Ciudad de Buenos Aires, cabe destacar que -debido a la mayor precariedad habitacional de la población residente en las comunas 4 y 8 - estos fenómenos revisten de mayor gravedad en esta zona.

De este modo, las políticas de renovación, que vienen teniendo lugar -con matices y diversas temporalidades- desde fines de los ' 80 , junto con una serie de omisiones en relación a la regulación del mercado del suelo, de los alquileres y de los inmuebles ociosos (Rodriguez, Bañuelos y Mera, 2008) y la acentuación de ciertas políticas de cierre o clausura socio-territorial ${ }^{18}$ (Rodriguez y Di Virgilio, 2017) incidieron en el proceso de cambio sostenido que atraviesan los barrios del sur, afectando tanto su fisonomía, como los usos y precios del suelo (Herzer, 2008; 2012). Sin embargo, cabe señalar que "estas transformaciones no han sido homogéneas ni han afectado a todos los barrios por igual" (Herzer, 2012: 19). Como veremos, son modeladas tanto por las políticas públicas como por los procesos de resistencia y las características socio-territoriales preexistentes en estos barrios (Herzer, 2012;Rodriguez y Di Virgilio, 2014).

\section{Los distritos como una nueva propuesta para el "desarrollo del sur"}

A partir del año 2008, el GCBA formula una nueva propuesta frente al "deterioro de la zona sur". Así, se crean cuatro distritos económicos en los barrios del sur de la ciudad'19: el Distrito Tecnológico Parque Patricios (DT, ley 2972/08), el Distrito de las Artes en La Boca (DA, ley 4.353/12), el Distrito del Diseño en Barracas (DDi, ley 4761/13), y el Distrito del Deporte en Villa Soldati (DDe, ley 5235/14). Al desarrollarse de manera sistemática, estos distritos rompen con la lógica fragmentaria de las intervenciones urbanas precedentes (Goicoechea, 2016), a la vez que profundizan y extienden el proceso de renovación de las comunas 4 y 8 .

Ver CEyS, 2016; ACIJ, 2016 y las denuncias de Inquilinos Agrupados, http://www.inquilinosagrupados.com.ar/.

18 Con este término, las autoras se refieren a aquellas políticas que propician el orden socio-espacial establecido y aquellas que niegan los derechos de los sectores de menos ingresos. Para el caso de Buenos Aires se destacan: los desalojos a cuenta gotas, la punición de los procesos de ocupación de tierra y/o vivienda, el desfinanciamiento y la fragmentación de las políticas de producción de vivienda, la dilación en los procesos de urbanización de villas y el fomento a los procesos de mercantilización en el acceso a la vivienda en villas de la ciudad, entre otras.

19 Además de estos se crea el Distrito Audiovisual (DAu, ley 3876/11), en la zona norte de la Ciudad. Por tratarse de características territoriales muy diferentes, no incluimos su análisis en este trabajo. 
Figura No2:

Ubicación de los distritos económicos y los edificios del GCBA

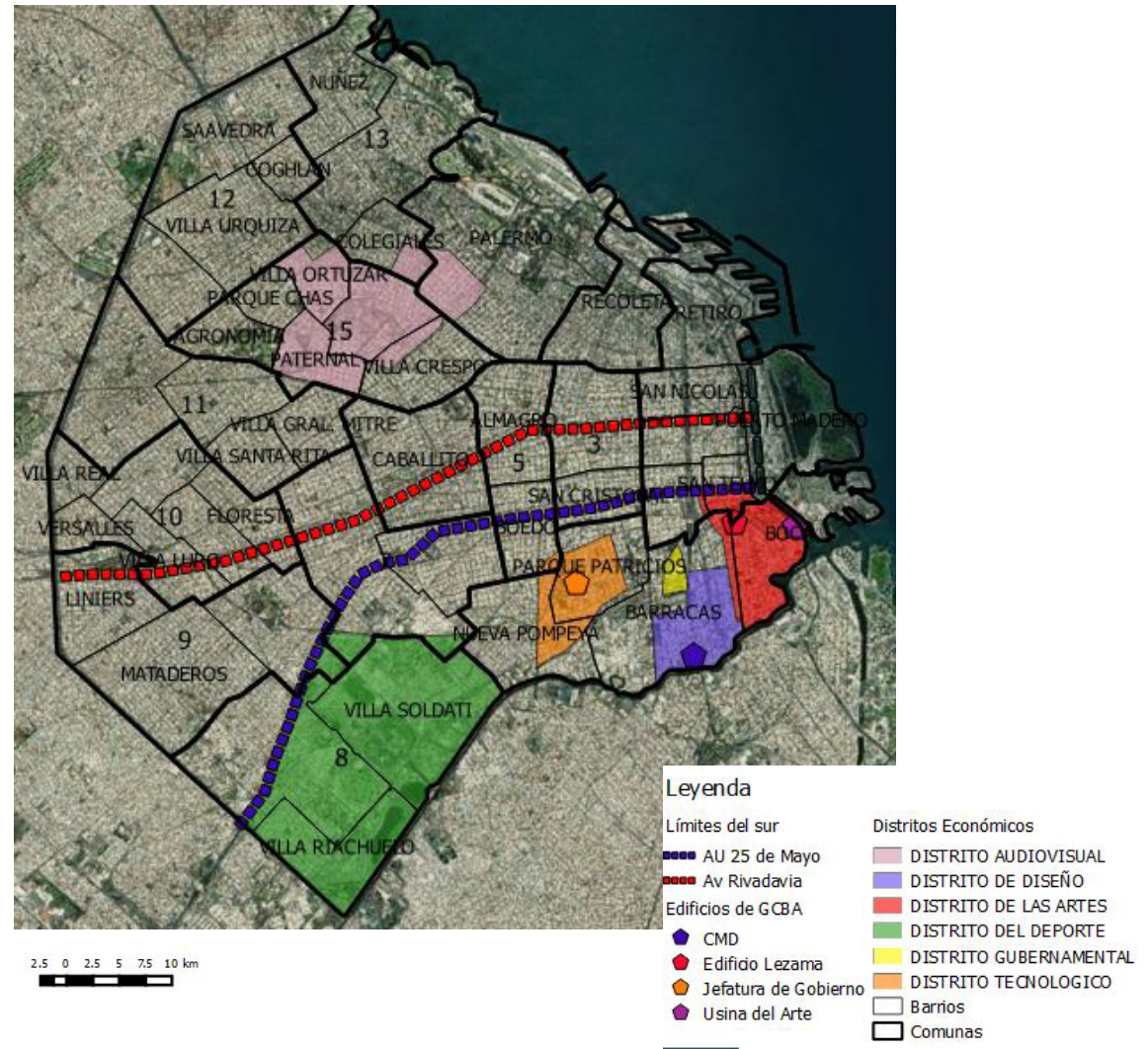

Fuente: elaboración propia en base a información del GCBA

Los cuatro distritos económicos del sur de la ciudad tienen en común la dependencia a una misma estructura organizativa, la conformación de un equipo de agentes que trabaja para cada distrito $^{20}$, y la sanción de una ley que regula sus beneficios y beneficiarios. Asimismo, todos ellos contemplan beneficios tributarios, financieros e inmobiliarios para las personas físicas o jurídicas que desarrollen las actividades promocionadas ${ }^{21}$. Como incentivos en común, se destacan, por un lado, la exención de entre 10 y 20 años de los impuestos de Ingresos Brutos (IIBB), Alumbrado Barrido y Limpieza ( $A B L)$, sello, y derecho de delineación y construcción; y por el otro, la formulación de líneas de crédito especiales a tasa subsidiada, a través del Banco Ciudad. De manera complementaria, en cada distrito se privilegian distintas estrategias, de acuerdo con las características

\footnotetext{
20 Esta estructura fue cambiando a lo largo del tiempo. Actualmente pertenecen a la Dirección General de Distritos, dentro de la Subsecretaría de Desarrollo Económico, en el Ministerio de Economía y Finanzas. El DA tiene, además, una coordinación encargada del desarrollo de contenidos y del vínculo de la comunidad, dentro del Ministerio de Cultura.

${ }^{21}$ En el DT se incentiva la instalación de empresas de Tecnología, Información y Comunicación (TIC). En el DA se promueve la radicación de emprendimientos culturales vinculados a las artes visuales y escénicas, la literatura y la música. En el DDi se busca la radicación de empresas dedicadas al diseño en distintos rubros (industrial, textil, gráfico, multimedial, publicitario, de calzado e indumentaria, de muebles, entre otros). En el DDe se promueve la instalación de firmas dedicadas a la fabricación de productos deportivos, la elaboración de embarcaciones deportivas, la construcción, mantenimiento y reparación de infraestructura deportiva, y de servicios profesionales ligados al desarrollo de actividades deportivas.
} 
de la actividad promocionada y del área en cuestión; con las negociaciones que se llevaron a cabo durante el proceso de aprobación de cada ley; y con el tipo de desarrollo territorial que se pretende promover en cada zona.

Con el fin de densificar la zona sur, la política de distritos incorpora beneficios para la promoción del desarrollo inmobiliario, que varían sutilmente en cada caso. Los barrios de La Boca y Barracas tienen un incentivo más fuerte, debido a que incorporan explícitamente la figura del "desarrollador o promotor de infraestructura"22, a quien se le permite computar el $25 \%$ del monto invertido en el desarrollo de la infraestructura como pago a cuenta de IIBB por todas las actividades que realicen en la ciudad. Este beneficio busca potenciar y extender los procesos de renovación urbana y de valorización inmobiliaria a otros sectores de estos barrios que todavía no fueron alcanzados por estas dinámicas. Sin embargo, por los rasgos de las actividades promovidas y las características socio-territoriales de estas zonas, estos incentivos no resultan aun suficientes para atraer los emprendimientos e inversiones deseadas, como se desarrollará más adelante.

En el distrito tecnológico, en tanto, no se incorpora esta figura ni este beneficio, pero sí se exime de pago del derecho de delineación y construcciones por un plazo de 10 años a todas las obras nuevas que se construyan en el distrito y que destinen más de la mitad de la superficie al desarrollo de las actividades promovidas. Además, con la sanción de la ley №3516 en el año 2010, se declara al polígono del distrito tecnológico como área destinada en forma prioritaria a las actividades TIC. Esto le permite a las empresas "tramitar habilitaciones con independencia del código de zonificación del suelo donde se instalen" (Goicoechea, 2016: 262). A pesar de tener un menor incentivo directo al desarrollo inmobiliario, este distrito es el que mayor dinamismo muestra, debido también a las características de la actividad promocionada y del área en cuestión. Finalmente, en Villa Lugano y Villa Soldati, no se menciona explícitamente la figura del desarrollador, pero se otorgan exenciones impositivas a las obras nuevas y remodelaciones de inmuebles con destino industrial, comercial y/o de servicios. De todas formas, en este distrito todavía no se registran empresas radicadas ni desarrollos por parte del capital privado. Por el contrario, el proceso de renovación está comandando por el Estado local a través de la puesta en el mercado de grandes extensiones de tierra de dominio público (ver Arqueros Mejica, 2017).

El impulso al mercado inmobiliario se acompaña de un rol activo por parte del Estado para convertir a estas zonas de la ciudad en sitios atractivos para la localización del capital. Se observa en todos los casos una fuerte inversión pública en infraestructura, transporte, seguridad y espacio público (Goicoechea, 2016; 2017). Estas intervenciones no se despliegan de manera uniforme en el territorio sino que se articulan con los procesos previos de renovación de cada zona, montándose sobre objetos, proyectos e institucionalidades heredadas. Las inversiones públicas se complementan, además, con el papel protagónico que asumen los funcionarios de los distritos del GCBA en la "atracción de inversiones". Estos equipos articulan con cámaras empresariales para buscar potenciales interesados en radicarse, y luego acompañan a las firmas en todo el proceso de instalación en los distritos. Asimismo, el carácter protagónico del Estado se materializa en las distintas sedes de oficinas públicas instaladas en cada uno de los distritos (edificio ex Canale,

Esta figura comprende a todos aquellos que realicen mejoras, reformas o construcciones en inmuebles destinados principalmente al desarrollo de las actividades promocionadas. 
Usina del Arte, CMD y Jefatura de Gobierno, ver Figura N²2 ${ }^{23}$. Así la "mudanza al sur" constituye un gesto político-discursivo que invita al privado a seguir los pasos del sector público.

\section{Distritos Económicos y valorización del mercado inmobiliario en el sur de la Ciudad Autónoma de Buenos Aires (CABA). Un análisis territorial comparativo}

A partir de la intervención pública en el sur de la ciudad, reseñada en el apartado anterior, cabe preguntarse por sus efectos territoriales concretos, a diez años de la creación del primer distrito económico. A continuación, se presenta un análisis de la dinámica del mercado inmobiliario en cada uno de ellos, a partir de diferentes tipologías ofertadas, entre el 2003 y el 2017. Así, se compara la variación porcentual del precio por metro cuadrado y la participación de las ofertas con respecto al total de la Ciudad para las diferentes unidades territoriales analizadas a lo largo de la serie disponible para cada tipología inmobiliaria. Las distintas unidades territoriales de control han permitido comparar las valorizaciones diferenciales en distintas áreas de la Ciudad, demostrando que dicho proceso responde a dinámicas territoriales específicas y localizadas, más allá de las dinámicas macroeconómicas generales. El hecho de identificar procesos territoriales específicos de valorización no implica, desde el punto de vista de este trabajo, comprenderlos en función de una o más variables aisladas. Por lo contrario, aquí concebimos a la política de distritos como el paraguas que engloba todas las medidas de "apalancamiento" del Estado, desde los beneficios impositivos hasta la inversión en infraestructura y servicios. En este sentido, las iniciativas estatales de renovación son consideradas un conjunto complejo y difícil de aislar al momento de analizar el impacto de los distritos en el mercado inmobiliario de estos barrios ${ }^{24}$.

\section{Oferta de terrenos}

La oferta de terrenos en venta es un importante indicador de la dinámica inmobiliaria. El precio de un terreno representa la renta capitalizable de suelo para un propietario y, a la vez, su incidencia en un desarrollo inmobiliario. En este caso, fueron analizadas 22.048 ofertas de terrenos en venta entre los años 2003 y 2017 para toda la Ciudad, que fueron agrupadas en cinco períodos: (1) 2003-2005; (2) 2006-2008; (3) 2009-2011; (4) 2012-2014 y (5) 2015-2017.

\footnotetext{
Cabe señalar que el distrito del deporte presenta algunos rasgos particulares en este sentido. Al momento de escritura del artículo no existen empresas radicadas y el equipo de este distrito se encuentra inactivo. El rol del Estado en este caso pasa más por la venta y/o concesión (dependiendo el caso) de terrenos públicos para la realización de una serie emprendimientos público-privados (Terminal de Omnibus Delepiane; Centro de Concentración Logística; Estadio Roca; Villa Olímpica); complementado además por la urbanización de la Villa 20. Para profundizar, ver Arqueros Mejica (2017).

24 Algunos trabajos desarrollados en Estados Unidos y Canadá han intentado medir y analizar el impacto del metro en la colonización de nuevos mercados inmobiliarios, a través de la atracción tanto de inversiones como de grupos sociales de mayores ingresos o estatus (Kahn, 2007; Pollack et al., 2010; Grube-Cavers y Patterson, 2013). En líneas emparentadas, otros trabajos han intentado analizar esta misma relación entre transporte y gentrificación desde los cambios en el "capital espacial" en ciudades suizas, chilenas y argentinas (Reràt y Lees, 2011; Apaolaza et al., 2016). La evidencia empírica hallada por estos trabajos en ningún caso fue concluyente. Para el caso concreto de los efectos de la línea $\mathrm{H}$ del metro en área de estudio, informes técnicos inéditos realizados por la Secretaría de Planeamiento Urbano de la Ciudad de Buenos Aires (SPU-MDU) tampoco han podido comprobar una correlación lineal.
} 
A partir del Gráfico $N^{\circ} 1$ se observa la mayor representación de los barrios del sur (28\%) con respecto a los del norte (16\%) en la cantidad de terrenos ofrecidos a lo largo de toda la serie. De aquí puede inferirse la relación entre escasez de suelo y su elevado precio en el norte consolidado de la Ciudad. Por su parte, el conjunto de los distritos del sur representa menos del $8 \%$ del total de ofertas para toda la Ciudad, dando cuenta de una relativamente baja influencia en la dinámica inmobiliaria general. Dentro de los distritos del sur, el de las Artes es el principal oferente de suelo (23\%), seguido por el Distrito Tecnológico (16\%) y bastante más atrás, el del Diseño y Deporte (7 y $6 " \%$, respectivamente) (Gráfico $\left.N^{\circ} 2\right)$.

Gráfico 1:

Cantidad de ofertas de terrenos en venta distribuidas en Barrios del sur, Barrios del norte y total Distritos Económicos. Períodos 2003-2005 (1), 2006-2008 (2), 2009-2011 (3), 2012-2014 (4) y 2015-2017 (5).

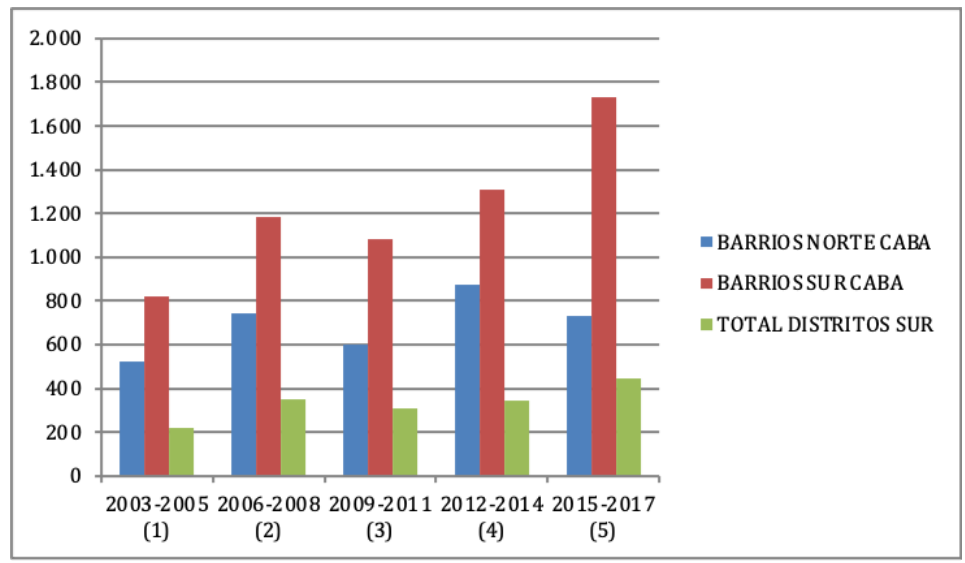

Fuente: elaboración propia en base a relevamientos propios y de MDU-GCBA. Aquí y en todos los gráficos subsiguientes, la sigla "CABA" refiere a la Ciudad Autónoma de Buenos Aires.

Gráfico 2:

Cantidad de ofertas de terrenos en venta en los distintos distritos económicos. Períodos 2003-2005 (1), 2006-2008 (2), 2009-2011 (3), 2012-2014 (4) у 2015-2017 (5).

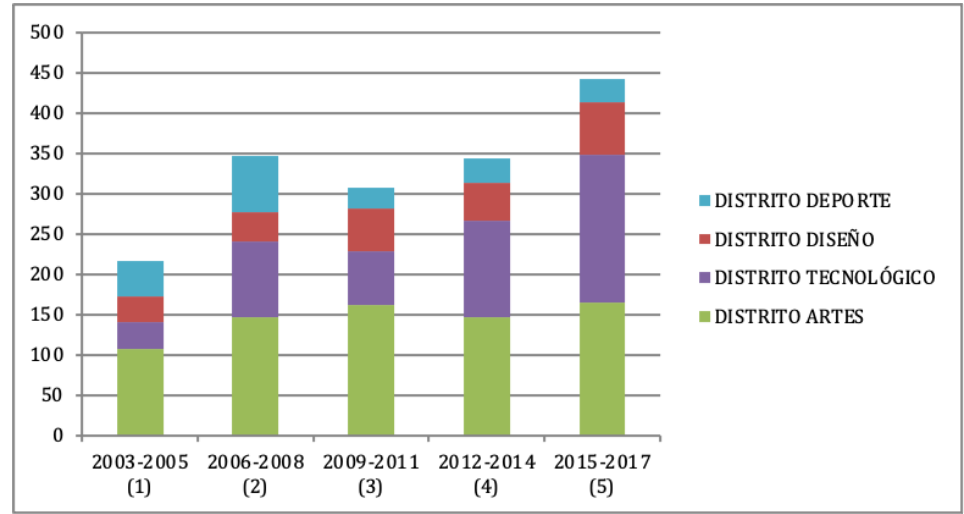

Fuente: elaboración propia en base a relevamientos propios y de MDU-GCBA 
Al analizar la evolución del precio promedio por metro cuadrado, la Cuadro $N^{\circ} 3$ permite constatar un significativo proceso de valorización en todas las unidades territoriales analizadas. Las principales variaciones se dan entre los períodos 1 y 2 , lo que factiblemente y de acuerdo con trabajos anteriores (Baer y Kauw, 2016) esté expresando un efecto general de recomposición del mercado inmobiliario, después de la fuerte crisis de 2001. No obstante, al comparar la variación entre los períodos 2 a 5 , es decir, entre el período inmediatamente anterior a la creación del primer Distrito y el último período relevado, es posible verificar que dicha valorización es más acelerada en las unidades territoriales del sur, que el norte y el promedio de la Ciudad. El Distrito Tecnológico se destaca con una valorización del $192 \%$, frente a un promedio de $83 \%$ para la Ciudad. Le sigue el del deporte, con un $107 \%$, luego el de las artes (91\%) y por último el del diseño (83\%). También es significativo que el total de las unidades territoriales desaceleran su valorización con el pasar del tiempo. El Distrito del Diseño es el más elocuente: entre los períodos 4 y 5 se desvaloriza en un 5\%. La única excepción se da en el Distrito del Deporte, que entre los períodos 3 y 4 experimenta una crecida (del 36 al 44\%), aunque el período siguiente se desploma (6\%).

Entre los períodos 2 y 3 es significativa la valorización que experimenta el DT, respecto del resto de las unidades territoriales ( $77 \%$, seguido de un $46 \%$ para el DDi; siendo el promedio de la Ciudad un $39 \%$ ). Es precisamente en este momento cuando se conoce públicamente y se sanciona la ley de creación del distrito tecnológico, a la vez que se inauguran las estaciones del metro (2007). La valorización que se observa para el Distrito del Diseño en este mismo período posiblemente guarde relación con la expectativa generada a partir del DT, tal como fue señalado por el coordinador del DDi:

Nosotros partimos de una experiencia previa, que es la del tecnológico en donde la tasa de incidencia, o sea el valor de la tierra se había triplicado. Entonces, como había ya actores que estaban alertados de eso, hablo de inmobiliarias, algunos dueños, ya empezaban con este distrito del diseño con un piso un poco más alto que el piso en general (Entrevista a coordinador del DDi, diciembre de 2018).

También ligado al DT, es factible que la caída de un $5 \%$ entre los períodos 4 y 5 del DDi se deba a un ajuste de las expectativas generadas por el "éxito" del Distrito lindero. Para el resto de los Distritos no parece haber una tendencia clara, lo que lleva a relativizar el efecto territorial de esta política, al menos hasta el momento.

\section{Cuadro N³:}

Precio promedio (U\$S) por metro cuadrado y su variación porcentual, para las ofertas de terrenos en venta en unidades territoriales seleccionadas. Períodos 2003-2005 (1), 2006-2008 (2), 2009-2011 (3), 2012-2014 (4) y 2015-2017 (5)

\begin{tabular}{|c|c|c|c|c|c|c|c|c|c|c|}
\hline PROMEDIO USD/M2 & $\begin{array}{c}2003-2005 \\
\text { (1) }\end{array}$ & $\begin{array}{c}2006-2008 \\
\text { (2) }\end{array}$ & $\begin{array}{c}2009-2011 \\
\text { (3) }\end{array}$ & $\begin{array}{c}2012-2014 \\
\text { (4) }\end{array}$ & $\begin{array}{c}2015-2017 \\
\text { (5) }\end{array}$ & $\begin{array}{c}\text { variac porc } \\
1 \text { y } 2\end{array}$ & $\begin{array}{c}\text { variac porc } \\
2 y 3\end{array}$ & $\begin{array}{c}\text { va riac porc } \\
3 \text { y } 4\end{array}$ & $\begin{array}{c}\text { variac porc } \\
4 \text { y } 5\end{array}$ & $\begin{array}{c}\text { variac porc } \\
2 \text { y } 5\end{array}$ \\
\hline CABA & 576 & 1.019 & 1.416 & 1.773 & 1.863 & $77 \%$ & $39 \%$ & $25 \%$ & $5 \%$ & $83 \%$ \\
\hline BARRIOS NORTE CABA & 1.099 & 1.786 & 2.241 & 2.786 & 2.965 & $63 \%$ & $25 \%$ & $24 \%$ & $6 \%$ & $66 \%$ \\
\hline BARRIOS SUR CABA & 348 & 687 & 969 & 1.293 & 1.422 & $97 \%$ & $41 \%$ & $33 \%$ & $10 \%$ & $107 \%$ \\
\hline DISTRITO DISEÑO & 254 & 634 & 925 & 1.219 & 1.157 & $150 \%$ & $46 \%$ & $32 \%$ & $-5 \%$ & $83 \%$ \\
\hline DISTRITO ARTES & 260 & 576 & 831 & 974 & 1.098 & $121 \%$ & $44 \%$ & $17 \%$ & $13 \%$ & $91 \%$ \\
\hline DISTRITO TECNOLÓGICO & 234 & 486 & 858 & 1.142 & 1.418 & $108 \%$ & $77 \%$ & $33 \%$ & $24 \%$ & $192 \%$ \\
\hline DISTRITO DEPORTE & 149 & 315 & 428 & 617 & 653 & $112 \%$ & $36 \%$ & $44 \%$ & $6 \%$ & $107 \%$ \\
\hline
\end{tabular}

Fuente: elaboración propia en base a relevamientos propios y de MDU-GCBA 


\section{Oferta de departamentos}

Las ofertas de tipologías residenciales, como los departamentos, son un indicador sensible para observar procesos de renovación urbana excluyente, en tanto que representa en concreto la posibilidad de residir en la Ciudad. En este caso, fueron analizadas 158.068 ofertas de departamentos en venta entre los años 2003 y 2016 para toda la Ciudad, que fueron agrupadas en cinco períodos: (1) 2003-2005; (2) 2006-2008; (3) 2009-2011; (4) 2012-2014 y (5) 2015-2016.

Con respecto a la distribución territorial de las ofertas, el Gráfico №3 permite observar, al contrario que con los terrenos, la concentración sobre todo en los barrios del norte respecto a los del sur, así como la pequeña participación de los Distritos del sur en el mercado de departamentos de la Ciudad. De estos, el DA es el que concentra la mayor cantidad de ofertas, seguido muy por detrás por el DDi (Gráfico №4).

\section{Gráfico No3:}

Cantidad de ofertas de terrenos en venta distribuidas en Barrios del norte, Barrios del sur y total Distritos Económicos. Períodos 2003-2005 (1), 2006-2008 (2), 2009-2011 (3), 2012-2014 (4) y 2015-2016 (5).

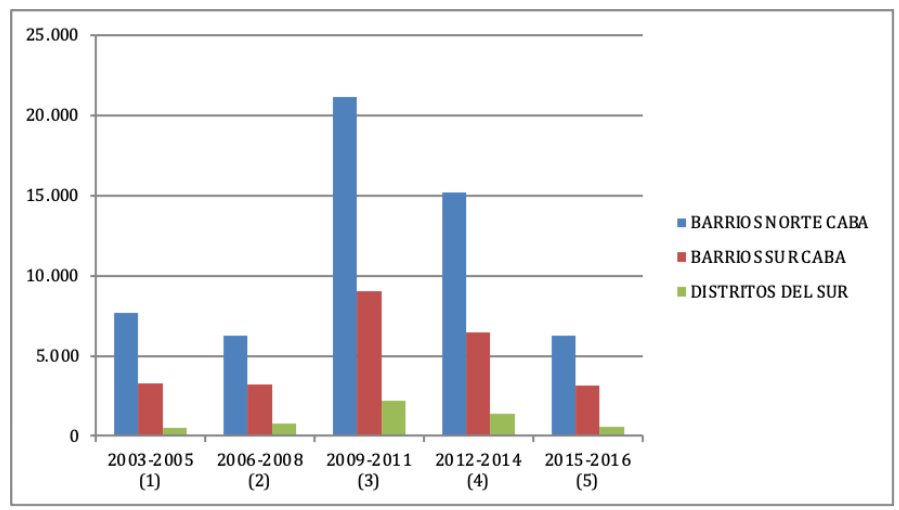

Fuente: elaboración propia en base a relevamientos propios y de MDU-GCBA

Gráfico 4:

Cantidad de ofertas de terrenos en venta en los distintos distritos económicos. Períodos 2003-2005 (1), 2006-2008 (2), 2009-2011 (3), 2012-2014 (4) y 2015-2016 (5).

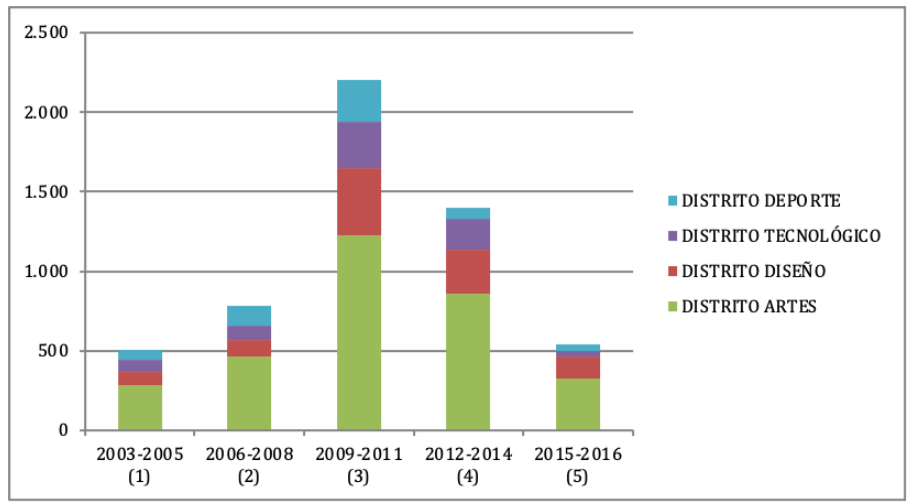

Fuente: elaboración propia en base a relevamientos propios y de MDU-GCBA 
Con respecto a la valorización de los departamentos, el Cuadro N4 permite observar que a lo largo de la serie (excluyendo el período 1 por los motivos señalados para el análisis de terrenos) el DA es el único Distrito que mantiene una valorización a la par de la tendencia general de la ciudad, probablemente traccionada por la dinámica propia del barrio de San Telmo, más que por efecto de la política de distritos. El resto se valorizan más lentamente que el promedio de la CABA, y es significativo que la unidad Barrios del sur es la única que supera esta tendencia ( $97 \%$, frente al $78 \%$ para la $\mathrm{CABA}$ ). Esto señala que la acelerada valorización del sur de la Ciudad a la que refieren otros autores (Baer, 2011; Goicoechea, 2016) no se estaría explicando por la política de Distritos, por lo menos para el caso del mercado de departamentos.

\section{Cuadro N4:}

Precio promedio (U\$S) por metro cuadrado y su variación porcentual, para las ofertas de departamentos en venta en unidades territoriales seleccionadas. Períodos 2003-2005 (1), 2006-2008 (2), 2009 2011 (3), 2012-2014 (4) y 2015-2016 (5).

\begin{tabular}{|c|c|c|c|c|c|c|c|c|c|c|}
\hline PROMEDIO USD/M2 & $\begin{array}{c}2003-2005 \\
\text { (1) }\end{array}$ & $\begin{array}{c}2006-2008 \\
\text { (2) }\end{array}$ & $\begin{array}{c}2009-2011 \\
\text { (3) }\end{array}$ & $\begin{array}{c}2012-2014 \\
\text { (4) }\end{array}$ & $\begin{array}{c}2015-2016 \\
\text { (5) }\end{array}$ & $\begin{array}{c}\text { variac porc } \\
1 \text { y } 2\end{array}$ & $\begin{array}{c}\text { variac porc } \\
2 \text { y } 3\end{array}$ & $\begin{array}{c}\text { variac porc } \\
3 \text { y } 4\end{array}$ & $\begin{array}{c}\text { variac porc } \\
4 \quad \text { y } 5\end{array}$ & $\begin{array}{c}\text { variac porc } \\
2 \text { Y } 5\end{array}$ \\
\hline CABA & 699 & 1.384 & 1.860 & 2.289 & 2.462 & $98 \%$ & $34 \%$ & $23 \%$ & $8 \%$ & $78 \%$ \\
\hline BARRIOS NORTE CABA & 867 & 1.701 & 2.234 & 2.679 & 2.979 & $96 \%$ & $31 \%$ & $20 \%$ & $11 \%$ & $75 \%$ \\
\hline BARRIOS SUR CABA & 525 & 1.046 & 1.417 & 1.822 & 2.059 & $99 \%$ & $35 \%$ & $29 \%$ & $13 \%$ & $97 \%$ \\
\hline DISTRITO DISEÑO & 565 & 1.115 & 1.500 & 1.876 & 1.947 & $97 \%$ & $35 \%$ & $25 \%$ & $4 \%$ & $75 \%$ \\
\hline DISTRITO ARTES & 510 & 1.060 & 1.446 & 1.749 & 1.883 & $108 \%$ & $36 \%$ & $21 \%$ & $8 \%$ & $78 \%$ \\
\hline DISTRITO TECNOLÓGICO & 451 & 959 & 1.322 & 1.922 & 1.623 & $113 \%$ & $38 \%$ & $45 \%$ & $-16 \%$ & $69 \%$ \\
\hline DISTRITO DEPORTE & 392 & 769 & 1.000 & 1.416 & 1.196 & $96 \%$ & $30 \%$ & $42 \%$ & $-16 \%$ & $56 \%$ \\
\hline
\end{tabular}

Fuente: elaboración propia en base a relevamientos propios y de MDU-GCBA

\section{Oferta de oficinas}

Dado que la actividad productiva es central en el planteo de los Distritos Económicos, el análisis de la evolución del mercado de oficinas se constituye como un importante indicador de nueva actividad económica, especialmente en algunos de los Distritos, como veremos a continuación. Para el caso de esta tipología inmobiliaria, se analizaron 4.843 ofertas, distribuidas en tres años: 2014, 2016 y 2017. Dada la breve serie de datos disponible, no se organizaron periodizaciones.

A partir de la Cuadro $N^{\circ} 5$ se observa la escasa incidencia de las oficinas en los Distritos del Sur, que participan entre un 2 y $3 \%$ del total de las ofertas de la Ciudad. La localización de las actividades empresariales se concentra en el Microcentro (un $45 \%$ en los barrios San Nicolás y Monserrat) y zona norte de la ciudad (23\%), representa menos del $8 \%$ en la zona sur.

Cuadro N5:

Cantidad de ofertas de oficinas en venta para unidades territoriales seleccionadas. Años 2014, 2016 y 2017.

\begin{tabular}{|c|c|c|c|c|c|c|c|c|}
\hline \multirow[b]{2}{*}{ CANTIDAD DE OFERTAS } & \multicolumn{2}{|c|}{$2014(1)$} & \multicolumn{2}{|c|}{$2016(2)$} & \multicolumn{2}{|c|}{$2017(3)$} & \multicolumn{2}{|c|}{ TOTAL 2014-2017 } \\
\hline & $\begin{array}{l}\text { Total de } \\
\text { ofertas }\end{array}$ & $\begin{array}{c}\text { Participación } \\
\text { respecto al } \\
\text { total }\end{array}$ & $\begin{array}{c}\text { Total de } \\
\text { ofertas }\end{array}$ & $\begin{array}{c}\text { Participación } \\
\text { respecto al } \\
\text { total }\end{array}$ & $\begin{array}{l}\text { Total de } \\
\text { ofertas }\end{array}$ & $\begin{array}{c}\text { Participación } \\
\text { respecto al } \\
\text { total }\end{array}$ & $\begin{array}{l}\text { Total de } \\
\text { ofertas }\end{array}$ & $\begin{array}{c}\text { Participación } \\
\text { respecto al } \\
\text { total }\end{array}$ \\
\hline CABA & 1.862 & $100,0 \%$ & 1.060 & $100,0 \%$ & 1.921 & $100,0 \%$ & 4.843 & $100,0 \%$ \\
\hline MICROCENTRO & 864 & $46,4 \%$ & 431 & $40,7 \%$ & 884 & $46,0 \%$ & 2.179 & $45,0 \%$ \\
\hline BARRIOS NORTE CABA & 430 & $23,1 \%$ & 267 & $25,2 \%$ & 429 & $22,3 \%$ & 1.126 & $23,3 \%$ \\
\hline BARRIOS SUR CABA & 149 & $8,0 \%$ & 59 & $5,6 \%$ & 128 & $6,7 \%$ & 336 & $6,9 \%$ \\
\hline TOTAL DISTRITOS DEL SUR & 38 & $2,0 \%$ & 24 & $2,3 \%$ & 62 & $3,2 \%$ & 124 & $2,6 \%$ \\
\hline
\end{tabular}




\begin{tabular}{|c|c|c|c|c|c|c|c|c|}
\hline DISTRITO DISEÑO & 0 & $0,0 \%$ & 3 & $0,3 \%$ & 3 & $0,2 \%$ & 6 & $0,1 \%$ \\
\hline DISTRITO ARTES & 18 & $1,0 \%$ & 14 & $1,3 \%$ & 22 & $1,1 \%$ & 54 & $1,1 \%$ \\
\hline DISTRITO TECNOLÓGICO & 19 & $1,0 \%$ & 5 & $0,5 \%$ & 36 & $1,9 \%$ & 60 & $1,2 \%$ \\
\hline DISTRITO DEPORTE & 1 & $0,1 \%$ & 2 & $0,2 \%$ & 1 & $0,1 \%$ & 4 & $0,1 \%$ \\
\hline
\end{tabular}

Fuente: elaboración propia en base a relevamientos propios y de MDU-GCBA

Las ofertas entre los Distritos del Sur (Gráfico $N^{\circ} 6$ ) se distribuyen casi por completo entre los distritos de las artes y tecnológico. En el caso del primero de ellos, la oferta disponible se explica por la dinámica del microcentro, ya que las ofertas registradas se localizan fundamentalmente en el barrio contiguo de San Telmo. Es decir, que la oferta de oficinas no puede comprenderse como un efecto del Distrito. Lo contrario sucede en el DT, donde la oferta de oficinas previo a la Ley era prácticamente inexistente. Tal como apunta un importante agente inmobiliario de la zona:

Lo que se empezó a construir, después del distrito, hacían falta oficinas. Había demanda de empresas que querían venir a radicarse. (...) Con lo cual la tierra disponible, en zonas en las cuales se puede construir en altura, se empezaron a hacer edificios de oficina porque obviamente estaba la necesidad (Entrevista a inmobiliaria del DT, junio de 2017).

Gráfico N6:

Distribución de ofertas de oficina en venta entre los Distritos del sur. Años 2014, 2016 y 2017.

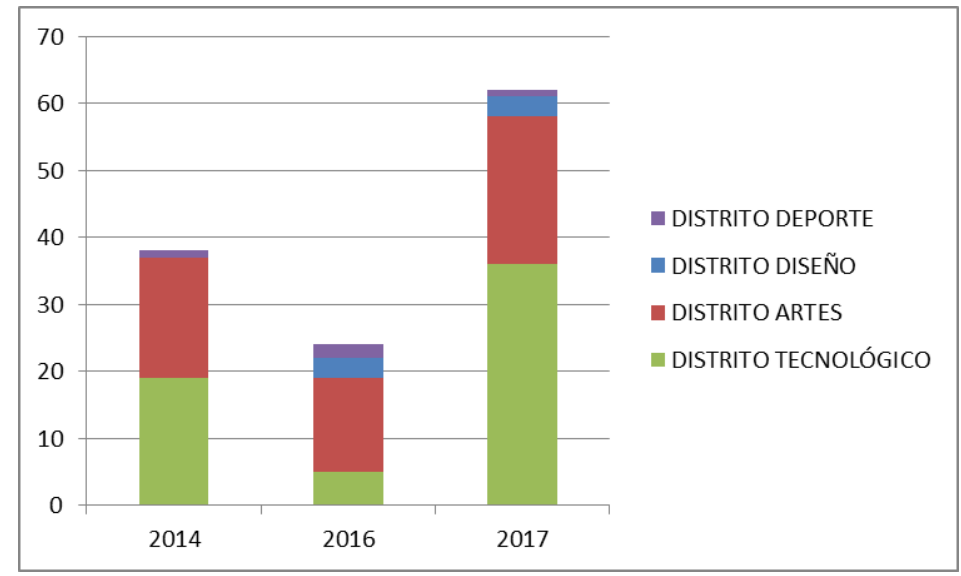

Fuente: elaboración propia en base a relevamientos propios y de MDU-GCBA

Aunque la incidencia en el mercado de oficinas de los Distritos es muy baja en el marco del total de la Ciudad, es interesante observar lo que sucede en términos de valorización, sobre todo en el Distrito Tecnológico, que experimenta un importante salto. Los datos del Cuadro $\mathrm{N}^{\circ} 6$ señalan que para el año 2017 el precio promedio de la CABA fue de U\$S 2.136 el metro cuadrado, y de U\$S 1.722 para los Barrios del Sur. Los valores del DT (U\$S 1.823) superan a los de los barrios del sur (U\$S 1.722) y están muy por encima del resto de los distritos. Es especialmente significativa la acelerada valorización del DT, de un $20 \%$ entre los extremos de la serie, frente a un $9 \%$ del promedio de la CABA. Si bien no forma parte del foco de este trabajo, cabe señalar que los precios en dólares de los alquileres de oficinas también experimentaron un fuerte incremento en el área del Distrito Tecnológico, 
superando incluso los valores del Microcentro ${ }^{25}$. Estos datos permiten confirmar la gran incidencia del DT -orientado a la radicación de oficinas- en este submercado inmobiliario en el sur de la Ciudad, inaugurando un "nuevo" nicho en la zona. Los barrios del sur se valorizan más lentamente que la media de la Ciudad, y en todos los Distritos -salvo el ya mencionado DT- los precios caen a lo largo de la serie. Este comportamiento del mercado tiene sentido, en tanto que los distritos del deporte, artes y diseño requieren otras tipologías (galpones y locales comerciales, principalmente).

\section{Cuadro N6:}

Precio promedio (U\$S) por metro cuadrado y su variación porcentual, para las ofertas de oficinas en venta en unidades territoriales seleccionadas. Años 2014, 2016 y 2017.

\begin{tabular}{|c|c|c|c|c|c|c|}
\hline PROMEDIO USD/M2 & $\mathbf{2 0 1 4}$ & $\mathbf{2 0 1 6}$ & $\mathbf{2 0 1 7}$ & $\begin{array}{c}\text { variac porc } \\
\mathbf{2 0 1 4 - 2 0 1 6}\end{array}$ & $\begin{array}{c}\text { variac porc } \\
\mathbf{2 0 1 6 - 2 0 1 7}\end{array}$ & $\begin{array}{c}\text { variac porc } \\
\mathbf{2 0 1 4 - 2 0 1 7}\end{array}$ \\
\hline CABA & 1.963 & 2.069 & 2.136 & $5 \%$ & $3 \%$ & $9 \%$ \\
\hline BARRIOS NORTE CABA & 2.584 & 2.560 & 2.842 & $-1 \%$ & $11 \%$ & $10 \%$ \\
\hline BARRIOS SUR CABA & 1.647 & 1.811 & 1.722 & $10 \%$ & $-5 \%$ & $5 \%$ \\
\hline DISTRITO DISEÑO & $/ /$ & 1.477 & 1.280 & $/ /$ & $-13 \%$ & $/ /$ \\
\hline DISTRITO ARTES & 1.711 & 1.886 & 1.557 & $10 \%$ & $-17 \%$ & $-9 \%$ \\
\hline DISTRITO TECNOLÓGICO & 1.521 & 2.592 & 1.823 & $70 \%$ & $-30 \%$ & $20 \%$ \\
\hline DISTRITO DEPORTE & 916 & 881 & 609 & $-4 \%$ & $-31 \%$ & $-33 \%$ \\
\hline
\end{tabular}

Fuente: elaboración propia en base a relevamientos propios y de MDU-GCBA

\section{Oferta de locales comerciales}

Finalmente, la dinámica inmobiliaria de los locales comerciales también es un importante indicador de renovación urbana. Aunque excede a los límites de este trabajo el análisis del recambio comercial en las áreas de renovación de los Distritos (para un análisis sobre el DT ver CEDEM, 2014), la dinámica de ofertas y el proceso de valorización arrojan algunas pistas en este sentido.

La Cuadro $\mathrm{N}^{\circ} 7$ da cuenta de la pequeña participación que tienen los Distritos del sur en el mercado de locales comerciales, promediando un $7 \%$ para toda la serie ( 1.175 de 17.487 para el total de la Ciudad).

\section{Cuadro $\mathrm{N}^{\circ} 7$ :}

Cantidad de ofertas de locales comerciales en venta en Barrios del norte, Barios del sur y total de Distritos del sur. Períodos 2005-2007 (1), 2008-2010 (2), 2011-2013 (3) y 2014-2017 (4)

\begin{tabular}{|c|c|c|c|c|c|c|c|c|c|c|}
\hline \multirow[b]{2}{*}{ CANTIDAD DE OFERTAS } & \multicolumn{2}{|c|}{$2005-2007$ (1) } & \multicolumn{2}{|c|}{$2008-2010(2)$} & \multicolumn{2}{|c|}{$2011-2013(3)$} & \multicolumn{2}{|c|}{$2014-2017$ (4) } & \multicolumn{2}{|c|}{ TOTAL 2005-2017 } \\
\hline & $\begin{array}{c}\text { Total de } \\
\text { ofertas }\end{array}$ & $\begin{array}{c}\text { Participación } \\
\text { respecto al } \\
\text { total }\end{array}$ & $\begin{array}{l}\text { Total de } \\
\text { ofertas }\end{array}$ & $\begin{array}{c}\text { Participación } \\
\text { respecto al } \\
\text { total }\end{array}$ & $\begin{array}{c}\text { Total de } \\
\text { ofertas }\end{array}$ & $\begin{array}{c}\text { Participación } \\
\text { respecto al } \\
\text { total }\end{array}$ & \begin{tabular}{|c}
$\begin{array}{c}\text { Total } \\
\text { de } \\
\text { ofertas }\end{array}$ \\
\end{tabular} & $\begin{array}{c}\text { Participación } \\
\text { respecto al } \\
\text { total }\end{array}$ & $\begin{array}{l}\text { Total de } \\
\text { ofertas }\end{array}$ & $\begin{array}{c}\text { Participación } \\
\text { respecto al } \\
\text { total }\end{array}$ \\
\hline TOTAL CABA & 3.337 & $100,0 \%$ & 3.199 & $100,0 \%$ & 3.298 & $100,0 \%$ & 7.653 & $100,0 \%$ & 17.487 & $100,0 \%$ \\
\hline BARRIOS NORTE CABA & 482 & $14,4 \%$ & 466 & $14,6 \%$ & 682 & $20,7 \%$ & 1.641 & $21,4 \%$ & 3.271 & $18,7 \%$ \\
\hline BARRIOS SUR CABA & 908 & $27,2 \%$ & 907 & $28,4 \%$ & 697 & $21,1 \%$ & 1.532 & $20,0 \%$ & 4.044 & $23,1 \%$ \\
\hline TOTAL DISTRITOS DEL SUR & 311 & $9 \%$ & 308 & $10 \%$ & 177 & $5 \%$ & 379 & $5 \%$ & 1.175 & $7 \%$ \\
\hline DISTRITO DISEÑO & 28 & $0,8 \%$ & 39 & $1,2 \%$ & 43 & $1,3 \%$ & 58 & $0,8 \%$ & 168 & $1,0 \%$ \\
\hline DISTRITO ARTES & 172 & $5,2 \%$ & 186 & $5,8 \%$ & 94 & $2,9 \%$ & 226 & $3,0 \%$ & 678 & $3,9 \%$ \\
\hline DISTRITO TECNOLÓGICO & 46 & $1,4 \%$ & 44 & $1,4 \%$ & 29 & $0,9 \%$ & 72 & $0,9 \%$ & 191 & $1,1 \%$ \\
\hline DISTRITO DEPORTE & 65 & $1,9 \%$ & 39 & $1,2 \%$ & 11 & $0,3 \%$ & 23 & $0,3 \%$ & 138 & $0,8 \%$ \\
\hline
\end{tabular}

Fuente: elaboración propia en base a relevamientos propios y de MDU-GCBA

25 Diferentes agentes del sector inmobiliario de la zona coinciden en que actualmente los alquileres de oficinas en el DT alcanzan los $18 / 20$ dólares por metro cuadrado; mientras que en el Microcentro estos valores no llegan a los 15 dólares. 
Dentro de esa gran unidad territorial, se destaca el Distrito de las Artes en todos los períodos. Esto parece estar relacionado, por un lado, a la dinámica comercial vinculada al turismo que tiene gran incidencia en el entorno del Parque Lezama y el incipiente polo gastronómico de Av. Caseros; y en la zona de Caminito, el enclave turístico más importante de la ciudad. Asimismo, se asocia a las actividades comerciales propias de las subcentralidades barriales de La Boca (sobre Av. Regimiento Patricios, y sobre la calle Olavarría).

Gráfico N8:

Distribución de ofertas de locales comerciales en venta entre los Distritos del sur. Períodos 2005-2007

(1), 2008-2010 (2), 2011-2013 (3) y 2014-2017 (4)

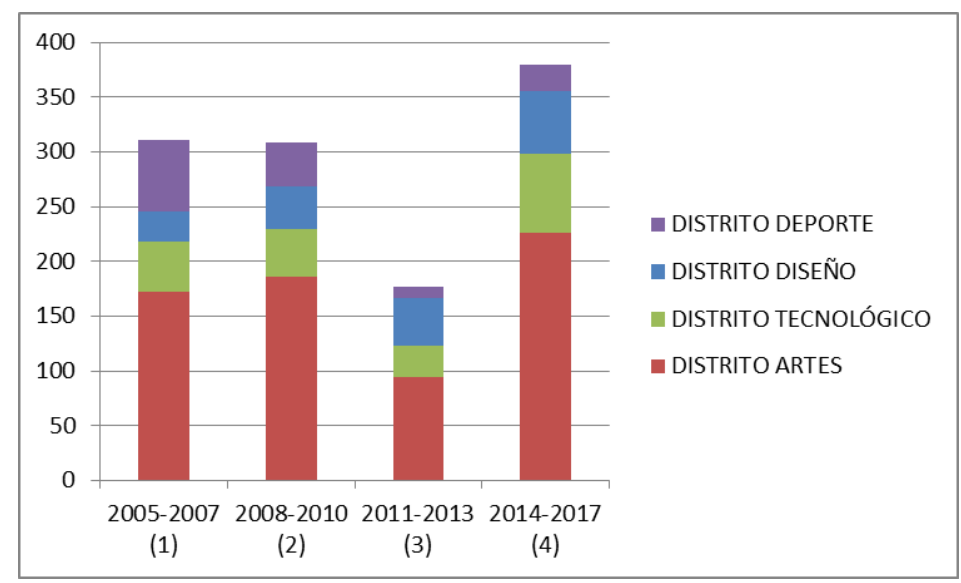

Fuente: elaboración propia en base a relevamientos propios y de MDU-GCBA

Con respecto a la dinámica general del mercado de locales comerciales, la Cuadro $\mathrm{N}^{\circ} 8$ permite constatar una gran valorización a lo largo de la serie para todos los distritos, superando (excepto el del Deporte) siempre el promedio de la Ciudad, tanto como el de los Barrios del sur. Esto último indica que, más allá de una limitada cantidad de ofertas, los precios de los locales en los distritos explican en gran medida la valorización general del sur, también para esta tipología inmobiliaria.

Para el caso del DDi, la importante valorización que se da entre el 2005 y 2010 coincide temporalmente con la progresiva concentración de locales de indumentaria de segunda selección (outlet), previa a la creación del distrito. Este incipiente polo, denominado "Barracas Outlet", es posteriormente presentado por el GCBA como parte del Distrito del Diseño, en la medida en que el diseño de indumentaria es una de las actividades promocionadas. Las ofertas correspondientes al Distrito del Deporte, en tanto, se concentran en las subcentralidades barriales, en torno a la estación de Lugano y el centro comercial de Villa Riachuelo, por lo que es poco probable que su dinámica comercial pueda explicarse por la política de distritos. Una vez más, se destaca el DT con una valorización del $183 \%$ frente a un $118 \%$ para el promedio de la Ciudad. En este caso, sí es clara la vinculación entre los procesos de renovación, a partir de la creación del Distrito Tecnológico y la instalación de la sede de gobierno, y la revitalización del mercado de locales comerciales. Relevamientos de campo previos y entrevistas, permiten apoyar estos datos del mercado inmobiliario: la generación de una nueva centralidad de escala urbana (y no la dinámica del 
viejo centro barrial), derivada de las 13.000 personas que se estima confluyen diariamente para trabajar, sumado a la promoción explícita del Estado local para la radicación de franquicias gastronómicas, se expresan en el crecimiento de los precios de los locales comerciales, tanto para la venta como para el alquiler ${ }^{26}$. Cabe señalar que el incremento de precios en lo que respecta a locales comerciales constituye una de las limitantes para el recambio comercial fomentado por el gobierno local, tal como lo explica uno de los agentes del DT:

(...) el tema de comercios, la dificultad que también la tienen las empresas, que es una dificultad global, es lo que te dije en un principio que el precio que tiene el distrito hoy, muchas empresas, sobre todos los comercios que no tienen beneficios impositivos, te dicen "mirá, es una locura". Por ejemplo, Café Martinez, que está a punto de venir al distrito, en su momento me dijo "mirá, ayudame a buscar alguna locación". (...) Porque era ayudarlos a encontrar una locación que sea acorde a lo que tiene que valer el distrito tecnológico. Porque me dicen "por lo que me quiere cobrar 100m2 en el distrito tecnológico, yo me abro un local en Pueyrredón y Santa Fe, de 200m2. Me están matando" (Entrevista a agente del equipo del DT, del GCBA, diciembre de 2018).

\section{Cuadro N8:}

Precio promedio (U\$S) por metro cuadrado y su variación porcentual, para las ofertas de locales comerciales en venta en unidades territoriales seleccionadas. Períodos 2005-2007 (1), 2008-2010 (2), 2011-2013 (3) y 2014-2017 (4)

\begin{tabular}{|c|c|c|c|c|c|c|c|c|}
\hline PROMEDIO USD/M2 & $\begin{array}{c}2005-2007 \\
\text { (1) }\end{array}$ & \begin{tabular}{|c|}
$2008-2010$ \\
$(2)$
\end{tabular} & $\begin{array}{c}2011-2013 \\
(3)\end{array}$ & \begin{tabular}{|c|}
$2014-2017$ \\
$(4)$
\end{tabular} & \begin{tabular}{|c|} 
variac porc \\
1 \ 2 \\
\end{tabular} & \begin{tabular}{|c|} 
variac porc \\
2 y 3 \\
\end{tabular} & $\begin{array}{c}\text { variac porc } \\
3 \text { y } 4\end{array}$ & \begin{tabular}{|c} 
variac porc \\
4 y 1
\end{tabular} \\
\hline CABA & 1.201 & 1.575 & 2.314 & 2.620 & $31 \%$ & $47 \%$ & $13 \%$ & $118 \%$ \\
\hline BARRIOS NORTE CABA & 2.040 & 2.345 & 3.048 & 3.544 & $15 \%$ & $30 \%$ & $16 \%$ & $74 \%$ \\
\hline BARRIOS SUR CABA & 805 & 1.162 & 1.572 & 1.847 & $44 \%$ & $35 \%$ & $17 \%$ & $129 \%$ \\
\hline DISTRITO DISEÑO & 770 & 1.383 & 2.178 & 2.163 & $79 \%$ & $58 \%$ & $-1 \%$ & $181 \%$ \\
\hline DISTRITO ARTES & 620 & 1.032 & 1.236 & 1.600 & $66 \%$ & $20 \%$ & $29 \%$ & $158 \%$ \\
\hline DISTRITO TECNOLÓGICO & 730 & 948 & 1.150 & 2.067 & $30 \%$ & $21 \%$ & $80 \%$ & $183 \%$ \\
\hline DISTRITO DEPORTE & 759 & 1.038 & 1.044 & 1.523 & $37 \%$ & $1 \%$ & $46 \%$ & $101 \%$ \\
\hline
\end{tabular}

Fuente: elaboración propia en base a relevamientos propios y de MDU-GCBA

\section{Reflexiones finales}

Cumplida una década desde la creación del primer Distrito Económico en el sur de la Ciudad, este trabajo procuró indagar sobre los efectos territoriales de estas políticas de renovación urbana, en particular en el mercado inmobiliario, desde una perspectiva comparada. Presentados por el ejecutivo local como una respuesta al histórico "desequilibro" entre una zona norte pujante y un área sur deteriorada y, a la vez, como una oportunidad para mejorar la inserción de Buenos Aires en la economía global; estos distritos constituyen el paraguas que nuclea las diversas iniciativas de renovación urbana en la zona sur de la ciudad.

Si bien no es el foco de este trabajo, en entrevistas con agentes del sector inmobiliario de la zona y con agentes del GCBA se menciona el fuerte incremento de los precios de alquiler de los locales comerciales, dado sobre todo por las expectativas de sus dueños. 
El análisis comparado da cuenta de la heterogeneidad en los resultados de una misma política, confirmando la importancia de un análisis situado de aquellas que circulan globalmente, muchas veces como "recetas" a aplicar, pero se resuelven y desenvuelven localmente, a partir de las fricciones que impone cada territorio. Por un lado, el trabajo permite observar las especificidades que han sido consideradas por la gestión local para cada Distrito, expresadas formalmente en cada Ley de distrito. Por otro lado, los datos del mercado inmobiliario permiten constatar que el comportamiento del mercado inmobiliario y del suelo es distinto según la tipología, lo que refuerza la importancia de este tipo de análisis para comprender la complejidad de las dinámicas de valorización y renovación urbana.

Con respecto a la cantidad de ofertas frente al total de la Ciudad, se corrobora que el mercado inmobiliario de los Distritos del sur en su conjunto es aún muy pequeño. Dentro de este grupo, el Distrito de las Artes concentra la mayor cantidad de ofertas de terrenos, departamentos y locales comerciales, posiblemente más vinculado a la dinámica del área central de San Telmo, que al efecto de la política de distritos.

En lo que respecta a los procesos de valorización del suelo y el mercado inmobiliario, los datos analizados muestran, por un lado, una acelerada valorización entre los períodos 2003-2005 y 2006-2008 para todas las unidades territoriales analizadas, probablemente como tendencia general de reacomodamiento luego de la crisis de 2001. Por otro lado, al analizar el comportamiento de los Distritos del sur a partir del período 2006-2008, los resultados son heterogéneos. En cuanto a los terrenos, es posible verificar que dicha valorización es más acelerada en las unidades territoriales del sur, que el norte y el promedio de la Ciudad, pudiéndose constatar un achicamiento entre la brecha inmobiliaria norte y sur. El Distrito Tecnológico se destaca entre todas las unidades territoriales, con una valorización del 192\%, frente a un promedio de $83 \%$ para la Ciudad. Con respecto a la oferta de departamentos, solo el Distrito de las Artes se valoriza igual que el promedio de la Ciudad (78\%), mientras que el resto de los Distritos del sur lo hace más lentamente. Sin embargo, la unidad Barrios del sur (97\%) lo hace por encima del promedio de la Ciudad. Esto señala que la acelerada valorización del sur de la Ciudad a la que refieren otros autores (Baer, 2011; Goicoechea, 2016) no se estaría explicando necesariamente por la política de distritos, por lo menos en lo que respecta al mercado de departamentos. En el mercado de oficinas nuevamente se destaca el Distrito Tecnológico, con un precio absoluto que está por encima de los barrios del sur (U\$S 1.823 y U\$S 1.722, respectivamente) y lejos del resto de los distritos. En términos relativos, es además especialmente significativa la acelerada valorización de este distrito, de un $20 \%$ entre los extremos de la serie, frente a un $9 \%$ para el promedio de la CABA. Por último, en lo que respecta a los locales comerciales, es significativo que todos los distritos del sur se valorizan por encima del promedio de la CABA y de los barrios del sur. Una vez más, entre los distritos se destaca el Tecnológico, con una valorización del $183 \%$ frente a un $118 \%$ para el promedio de la Ciudad.

El análisis muestra que, entre todos los distritos, es en el área del Tecnológico en donde se observa un mayor impacto en el mercado inmobiliario, como producto de esta política. Para comprender esto resultan clave varias cuestiones. Por un lado, es importante tener en cuenta la temporalidad extensa de los procesos urbanos. Los impactos de las políticas urbanas son observables a largo plazo, de ahí que -por el momento- sólo se puedan advertir cambios significativos en los barrios comprendidos por el Distrito Tecnológico, que es el primero en ser creado y tiene más años de vigencia. Otro aspecto a tener en cuenta son las características de la actividad promovi- 
da y los beneficios diferenciales que supone para cada caso. Las empresas TIC, promocionadas por el DT, constituyen un sector en crecimiento y de gran volumen de facturación, motivo por el cual las exenciones impositivas (fundamentalmente de IIBB) representan un beneficio económico de envergadura. Tal como lo explican agentes inmobiliarios de la zona, las exenciones tributarias compensan incluso el aumento de precios del suelo, generando la demanda necesaria para el crecimiento de la oferta de oficinas. Por último, los atributos de centralidad de esta zona (muy cercana al microcentro porteño, con buenos accesos desde y hacia la capital y el conurbano bonaerense, reforzados a su vez por las recientes inversiones públicas) resultan clave para la localización de las empresas TIC. Todo esto contribuye a hacer "más exitoso" este distrito, lo que incide en la dinámica inmobiliaria del área en cuestión.

En cuanto al Distrito de las Artes, se advierte que la dinámica de ofertas y precios también es significativa en algunos casos pero, a juzgar por la localización de las ofertas, es necesario tener en cuenta la influencia del área central y patrimonial de la Ciudad para su explicación. En efecto, tal como señalan algunos actores del distrito, aquí existen dificultades para atraer los emprendimientos culturales y desarrollos inmobiliarios deseados, dado que la mayoría de las actividades artísticas promovidas ya se encuentra exenta de IIBB en toda la ciudad; y que la exención del ABL no constituye un beneficio tan atractivo como para motivar una mudanza al distrito. A esto se le suman las representaciones negativas que aún pesan sobre algunos sectores de La Boca, al sur de este Distrito (Thomasz, 2016; 2017).

Los distritos del Deporte y del Diseño tienen aún importantes dificultades para llevar adelante la política. Inclusive en el primer caso, el proyecto se encuentra actualmente interrumpido. Algo de la valorización registrada en el Distrito del Diseño puede explicarse, según algunas entrevistas, por un "efecto arrastre" debido a su cercanía con el Distrito Tecnológico. En este caso, existen dificultades para atraer empresas asociadas al diseño debido a que, en muchos casos, su volumen de facturación no es tan grande como para que la exención de IIBB los persuada de mudarse al distrito. Esto se complementa, además, con el hecho de que es una industria que está atravesando serias dificultades económicas en el marco de la crisis actual, y con el hecho de que la incidencia del suelo en Barracas es similar a las de las zonas donde ya están instaladas.

Por razones de espacio, queda para un próximo trabajo un análisis de la localización de las ofertas dentro de cada Distrito, para poder explorar en qué medida la valorización de ciertos distritos (especialmente el de las Artes) se vincula con esta política económica específica, o con efectos territoriales previos (caso San Telmo y el turismo internacional y la valorización patrimonial). También resulta necesario complementar el análisis con otros indicadores de valorización inmobiliaria, como lo son la evolución de permisos de obra y los precios de alquileres, sobre todo en las tipologías de oficinas y locales.

Más allá de los heterogéneos resultados entre los distritos y las tipologías, este trabajo confirma la tendencia general de la valorización del sur en la Ciudad, "mejorando la equitatividad del suelo", según los propios términos del GCBA. Sin embargo, ninguna de las leyes de Distritos económicos incorpora mecanismos de sostenimiento de la población residente frente a estos procesos de encarecimiento, no solo del suelo sino de las condiciones de vida (a través, por ejemplo, del recambio de locales comerciales). Esto sólo puede acentuar y agravar aún más la situación, ya vulnerable, de las familias que residen en esta zona sur de Buenos Aires, como ya está sucediendo en La Boca (Distrito de las Artes), donde se están multiplicando los procesos de desalojo. 


\section{Bibliografía}

ACIJ. Buscar un techo. La problemática de los inquilinos y los alquileres en la Ciudad Autónoma de Buenos Aires. Colección Es Nuestra La Ciudad, 2, 2016.

ALMIRÓN, A., BERTONCELLO, R. y TRONCOSO, C. "Turismo, patrimonio y territorio. Una discusión de sus relaciones a partir de casos de Argentina", Estudios y Perspectivas en Turismo, vol. $15 \mathrm{~N}^{\circ} 2$, pp.101-124. Buenos Aires: CIET, 2006.

APAOLAZA, A. y Bossoer, L. Identificación de procesos de gentrificación a partir del análisis estadístico espacial de micro-unidades censales: Una propuesta para el caso de la Ciudad Buenos Aires. Working Papers Series Contested Cities. 2014.

ARQUEROS MEJICA, S. Procesos de producción social del hábitat y políticas públicas en las villas de la Ciudad de Buenos Aires. El caso del Barrio INTA. Universidad Torcuato Di Tella, 2013.

ARQUEROS MEJICA, S. La política de desarrollo de la Comuna 8 de la ciudad de Buenos Aires (1996-2015). Universidad de Buenos Aires, 2017.

BAER, L. El mercado de suelo formal de la Ciudad de Buenos Aires en su contexto metropolitano. Tesis doctoral. FFyL-UBA, 2011.

BAER, L. y KAUW, M. "Mercado inmobiliario y acceso a la vivienda formal en la Ciudad de Buenos Aires, y su contexto metropolitano, entre 2003 y 2013". EURE, vol 42, p. 5-25, 2016.

BAER, L. y DI GIOVAMBATTISTA, A. "Nuevas condiciones de acceso residencial en la Ciudad de Buenos Aires: el impacto del crédito y la macroeconomía en el mercado de compraventa y alquiler de vivienda formal", Voces en el fénix Nº71, 2018.

BLANCO, J. y APAOLAZA, R. "Políticas y geografías del desplazamiento. Contextos y usos conceptuales para el debate sobre gentrificación". En: Revista INVI, vol. 31, N 88. 73-98. Santiago de Chile, 2016.

CARAVACA, I., GONZALEZ ROMERO, G., FERNANDEZ SALINAS, V., GARCÍA, A. "Economía creativa en la aglomeración metropolitana de Sevilla: agentes, redes locales de colaboración y principales actuaciones." Asociación de Geógrafos Españoles, 63, 2013.

CARMAN, M., VIEIRA, N. y SEGURA, Ramiro. Segregación y diferencia en la ciudad. Quito: Flacso. 2013.

CEyS. La ciudad de Buenos Aires inquilinizada. Buenos Aires: GCBA, 2016.

DGEyC. Informe sobre Producto Bruto Geográfico de la ciudad de Buenos Aires. Buenos Aires. GBCA, 2015.

DI VIRGILIO, M., y GUEVARA, T. Gentrificación liderada por el Estado y empresarialismo urbano en la Ciudad Autónoma de Buenos Aires. Revista Estudios Sociales Contemporáneos, 11, 12-23, 2014. 
DíAZ, M., FERME, N., y RASPALL, T. Proyectos de Renovación Urbana en la Zona Sur de la Ciudad de Buenos Aires ¿Hacia una transformación de los usos del suelo urbano? El caso del Distrito Tecnológico de Parque Patricios. La Plata, 2010.

DÍAZ PARRA, I. "La gentrificación en la cambiante estructura socioespacial de la ciudad". Geo Crítica. Cuadernos Críticos de Geografía Humana, Universidad de Barcelona, 2013. Disponible en: http://www.ub.edu/geocrit/b3w-1030.htm

GOICOECHEA, M. E. ¿Desarrollo en el sur de Buenos Aires? Renovación urbana y valorización inmobiliaria. Bitácora Urbano Territorial [online], vol.28, n.2 2018.

GOICOECHEA, M. E. Distritos Creativos en el Sur de la Ciudad de Buenos Aires (2008-2015). Renovación urbana y nuevas lógicas de segregación. Vol 1. Universidad de Buenos Aires, 2016.

GOICOECHEA, M. E. Renovación urbana en el sur porteño y el "éxito" del Distrito Tecnológico. Algunas claves para comprender el dinamismo inmobiliario. Revista Quid 16, No6 especi, 30-61, 2017.

GOMEZ, M. y ZUNINO SINGH, D. “La (re)valorización de la zona sur y su patrimonio histórico-cultural como recurso turístico". En Herzer (coord), Con el corazón mirando al sur. Transformaciones en el sur de la ciudad de Buenos Aires. Buenos Aires: Espacio Editorial, 2008.

GONZALEZ REDONDO, C. Desarrollar el sur: el caso del distrito gubernamental en la Ciudad de Buenos Aires. Letra. Imagen. Sonido, VII(14), 181-200, 2015.

GONZALEZ REDONDO, C. Del distrito gubernamental a la nueva sede de gobierno. Disputas en torno al espacio urbano en la ciudad de Buenos Aires. Facultad de Filosofía y Letras, Universidad de Buenos Aires. Tesis de maestría inédita, 2018.

GONZALEZ REDONDO, C. "El distrito gubernamental de la ciudad de Buenos Aires. El dinámico vínculo entre la poliítica, el conflicto y el litigio judicial". Revista Dereito da Cidade, vol 10, n4, pp. 2671-2712, 2019.

GORELIK, A. (1998). La grilla y el parque. Buenos Aires: UNQ. 2016.

GORELIK, A. (2004). Miradas sobre Buenos Aires. Historia cultural y crítica urbana. Buenos Aires: Siglo XXI.

GRUBE-CAVERS, A. y Z. Patterson. Urban rapid rail transit and gentrification in Canadian urban centers - A survival analysis approach. Québec: Centre Interuniversitaire de Recherche sur les Réseaux d'Entreprise, la Logistique et le Transport (CIRRELT). 2013.

GUEVARA, T. Políticas habitacionales y procesos de producción del hábitat en la Ciudad de Buenos Aires. El caso de La Boca. Facultad de Ciencias Sociales, Universidad de Buenos Aires, 2010. 
GUEVARA, T. ¿La ciudad para quién? Transformaciones territoriales, políticas urbanas y proceso de producción del hábitat en la Ciudad de Buenos Aires, 1996-2011. Tesis de doctorado en Ciencias Sociales, Buenos Aires, Facultad de Ciencias Sociales, Universidad de Buenos Aires, 2015.

HARVEY, D. From managerialism to entrepreneurialism: the transformation in urban governance in late capitalism. Geografiska Annaler. Series B, Human Geography, 71(1), 3-17, 1989. Disponible en: https://doi.org/10.2307/490503

HERNÁNDEZ, S. Casa FOA y la emergencia del patrimonio industrial como valor específico del barrio de Barracas. XI Jornadas de Sociología. Facultad de Ciencias Sociales, Universidad de Buenos Aires, 2015.

HERNÁNDEZ, S. El rol del Centro Metropolitano de Diseño en el proceso de patrimonialización de Barracas (Ciudad de Buenos Aires ). Revista Quid 16, №6 Especi(Nº6 Especial), 94-119, 2017.

HERZER, H. Con el corazón mirando el sur: Transformaciones en el sur de la Ciudad de Buenos Aires. Buenos Aires: Espacio Editorial, 2008.

HERZER, H. Barrios al Sur. Renovación y pobreza en la Ciudad de Buenos Aires. Buenos Aires: Editorial Café de las Ciudades, 2012.

JANOSCHKA, M. y J. Sequera. Procesos de gentrificación y desplazamiento en América Latina, una perspectiva comparativista, en Desafíos metropolitanos. Un diálogo entre Europa y América Latina, Juan José Michelini (ed.), pp. 82-104. Catarata. Madrid. ISBN: 978-84-8319-887-2, 2014.

JARAMILLO, S.. "Acerca de la investigación en mercados de tierra urbana." En Ramírez Velázquez y Pradilla Cobos (comps.) Teorías sobre la ciudad en América Latina. México: UAM, 2014.

KAHN, M. Gentrification trends in new transit-oriented communities: Evidence from 14 cities that expanded and built rail transit systems. En: Real Estate Economics V.35 No2. Chicago: American Real Estate and Urban Economics Association. 2007.

LASH, S. y URRY, J. Economies of Signs and Space. London: Sage, 1994.

LAZZERETTI, L. El distrito cultural. In Soler, Vicente (coords) Los Distritos Industriales (Cajamar). Cajamar, 2008.

LERENA, N. “Crónica de un negocio anunciado: operaciones de recalificación industrial en BarceIona y Buenos Aires", URBS, vol 6, 2016.

LERENA, N. "Diez años del Distrito Tecnológico: políticas de desarrollo urbano y valorización inmobiliaria en el sur de la Ciudad de Buenos Aires" QUID 16, (11), 201-221, 2019. 
LÓPEZ-MORALES, E. Gentrificación en Chile: aportes conceptuales y evidencias para una discusión necesaria. Revista de geografía Norte Grande, (56), 31-52, 2013. https://dx.doi.org/10.4067/ S0718-34022013000300003

MARCUSE, P. "Gentrification, abandonment and displacement: connections, causes and policy responses in New York City". Journal of Urban and Contemporary Law 28, pp. 195-240, 1985.

MINISTERIO DE DESARROLLO URBANO. Modelo Territorial 2010-2060, edición literaria a cargo de Mauricio Macri, Daniel Chain y Héctor Lostri, Buenos Aires: GCBA, 2011.

MOLOTCH, H. "LA as design product: how art works in a regional economy”. En Scott y Soja (Eds) The City: Los Angeles and Urban Theory at the End of the Twentieth Century, pp. 225-275. University of California Press, Berkeley and Los Angeles, CA, 1996.

MERLINSKY, G. Políticas, derechos y justicia ambiental. El conflicto del Riachuelo. Buenos Aires. FCE, 2013.

OSZLAK, O., y O'DONNELL, G. Estado y políticas estatales en América Latina: hacia una estrategia de investigación. Cedes, (4), 98-128, 1981.

PRATT, A. C. "The cultural industries production system: a case study of employment change in Britain, 1984-91", Environment and Planning A 29, 1953-1974, 1997.

PÍREZ, P. Buenos Aires: la orientación neoliberal de la urbanización metropolitana. Sociologias, 18(42), 90-118, 2016.

POLLACK, S.; Bluestone, B. y Billingham, Ch. Maintaining diversity in America's transit-rich neighborhoods: tolos for equitable neighborhoods change. Boston: Dukakis Centre for Urban and Regional Policy. 2010.

PORTER, M. "The competitive advantage of the inner city", Harvard Bussiness Review, 1995. Disponible en: https://hbr.org/1995/05/the-competitive-advantage-of-the-inner-city\#

PORTER, M. Clusters and the new economic competition. Harvard Business Review, Nov-Dic, 1998.

PRADILLA COBOS, E. Las politicas y la planeación urbana en el neoliberalismo. In P. (comp) Brand (Ed.), La ciudad latinoamericana en el siglo XXI. Globalización, neoliberalismo, planeación (pp. 287-307). Medellín: Universidad Nacional de Colombia, 2009. Disponible en: http://www.emiliopradillacobos.com/TexABR2011/las políticas y la planeación urbana en el neoliberalismo.PDF

SCOTT, A. "The craft, fashion, and cultural products industries of Los Angeles: competitive dynamics and policy dilemmas in a multi-sectoral image-producing complex". Annals of the Association of American Geographers 86, 306-323, 1996. 
RERAT, P. y Lees, L. Spatial capital, gentrification and mobility: evidence from Swiss core cities. Transactions of the Institute of British Geographers, № 36. Londres: Royal Geographical Society. 2011.

RODRÍGUEZ, M. C. Estado, clases sociales y gentrificación. La política urbana como campo de disputa en tres barrios de la Ciudad de Buenos Aires. En Delgadillo, Díaz Parra y Salinas (Coords.) Perspectivas del estudio de la gentrificación en México y América Latina. México: UNAM, 2015.

RODRÍGUEZ, M. C, BAÑUELOS, C. y MERA, G. "Intervención - no intervención: ciudad y políticas públicas en el proceso de renovación del Área Sur de la Ciudad de Buenos Aires". En Herzer (organizadora) Con el corazón mirando al sur. Transformaciones en el sur de la ciudad de Buenos Aires. Buenos Aires: Espacio Editorial, 2008.

RODRÍGUEZ, M. C., y DI VIRGILIO, M. Ciudad de Buenos Aires: políticas urbanas neoliberales, transformaciones socio-territoriales y hábitat popular. Revista de Direito Da Cidade, 6(2), 323-347, 2014. Disponible en: https://doi.org/10.12957/rdc.2016.19115

RODRÍGUEZ, M. C., y DI VIRGILIO, M. "Procesos de gentrificación en la ciudad de Buenos Aires: notas históricas del detorrero de una invesitgación y de un equipo". Coloquio Clases sociales, renovación urbana y gentrificación. Agosto 2017, IIGG/UBA, 2017.

ROMERO, J. L. y ROMERO L. A. (dirs) Buenos Aires. Historia de cuatro siglos. Buenos Aires: Altamira. 1983.

ROMERO, J. L. (2009). “Buenos Aires: una historia”. En La ciudad occidental. Buenos Aires. Siglo XXI

SCHARAGER, A. "Cuando la justicia toca la puerta. Relocalizaciones y política en una villa de Buenos Aires.". Tesis de Maestría en Antropología Social. Instituto de Altos Estudios Sociales. Instituto de Desarrollo Económico y Social. Universidad Nacional de San Martín. Inédita, 2017.

SCILLAMÁ, M. Fábricas refuncionalizadas. ¿Dispositivos de integración o de segmentación urbana? Revista Quid 16, 4, 137-160, 2014.

SCOBIE, J. (1977). Buenos Aires. Del centro a los barrios 1870-1910. Buenos Aires: Ediciones SOLAR/HACHETTE

SILVESTRI, G., y GORELIK, A. (2000). "Ciudad y cultura urbana (1976-1999): el fin de la expansión”. En Romero, José Luis y Romero, Luis Alberto (dirs) Buenos Aires. Historia de cuatro siglos. Buenos Aires: Altamira.

SLATER, T. “Missing Marcuse: On gentrification and displacement". City, 13:2. pp. 292-311, 2009.

SMITH, N. Toward a Theory of Gentrification: A Back to the City Movement by Capital, not People. Journal of the American Planning Association, 1979, vol. 45, n 4, p. 538-548 
SOCOLOFF, I. "Polos, distritos y enclaves en Buenos Aires. De la pedagogía del inversor a la "inflación" de los precios del suelo". En: Murillo et al, compilado por Javier Martín, La ciudad empresa: espacios, ciudadanos y derechos bajo la lógica del mercado. Buenos Aires: Ediciones del CCC Floreal Gorrini, 2013.

SOCOLOFF, I., et al. "Gobernar Buenos Aires. Un estudio sobre las racionalidades políticas en torno al desarrollo local a partir del caso del Distrito Tecnológico de Parque Patricios (2008-2012). VII Jornadas de Sociología de La UNLP, 1-18, 2012.

THEODORE, N., PECK, J., y BRENNER, N. Urbanismo neoliberal: la ciudad y el imperio de los mercados. Temas Sociales SUR, (66), 12, 2009. Disponible en: www.sitiosur.cl

THOMASZ, A. G. Los nuevos distritos creativos de la Ciudad de Buenos Aires: la conversión del barrio de La Boca en el Distrito de las Artes; EURE (Santiago), 42(126), 123-144, 2016. https://doi. org/10.4067/S0250-71612016000200007

THOMASZ, A. G. Etnografía de un proceso de resemantización simbólico: del barrio de La Boca a Distrito de las Artes. Revista Quid 16, N6 especi, 67-93, 2017.

VECSLIR L. y CICCOLELLA, P. "Relocalización de las actividades terciarias y cambios en la centralidad en la Región Metropolitana de Buenos Aires". En: Revista de Geografía Norte Grande, Nro 49: 63-78, 2011. 